\title{
El derecho disciplinario ético-profesional y su lugar en el ordenamiento jurídico colombiano
}

The Ethical-Professional Disciplinary Law and its place in the Colombian legal order

\author{
A Lei Disciplinar Ético-Profissional e seu lugar na ordem jurídica \\ colombiana
}

\section{Guillermo Alfonso Maldonado Sierra ${ }^{1}$}

Recibido: 17 de abril de 2020

Aprobado: 8 de mayo de 2020

Publicado: 13 de julio de 2020

Cómo citar este artículo:

Guillermo Alfonso Maldonado Sierra. El derecho disciplinario ético-profesional y su lugar en el ordenamiento jurídico colombiano. DIXI 32, julio-diciembre 2020, 1-44.

DOI: https://doi.org/10.16925/2357-5891.2020.02.01

Artículo de investigación. https://doi.org/10.16925/2357-5891.2020.02.01

1 Abogado, especialista en Derecho Constitucional y magíster en Protección Social, Universidad Santo Tomás sede Bogotá.

Correo electrónico: guillermomaldonado@usantotomas.edu.co 


\section{Resumen}

Objetivo: describir las características generales del derecho disciplinario ético-profesional en Colombia.

Metodología: se llevó a cabo un estudio de corte cualitativo, documental, histórico-descriptivo y deductivo, con base en los regímenes disciplinarios de catorce códigos de ética profesional de algunas de las profesiones más tradicionales del país que han sido reglamentadas por el legislador colombiano.

Hallazgos: se logró una aproximación al concepto de derecho disciplinario ético-profesional, su naturaleza jurídica, sus diferencias sustanciales con el derecho disciplinario, su relación con el sistema de fuentes normativas colombiano, y una descripción de sus principales instituciones jurídico-procesales.

Conclusiones: se constató la enorme influencia que el derecho disciplinario ético-profesional recibe del derecho disciplinario y del derecho penal, y se evidenció una disparidad entre los regímenes disciplinarios de los códigos de ética profesional analizados, toda vez que algunos sobresalen por su garantismo procesal, mientras que los expedidos con antelación a la Constitución de 1991 están rezagados, por lo que urge su actualización para ponerlos a tono con los estándares constitucionales y convencionales que rigen en la materia.

Palabras clave: colegios profesionales, consejos profesionales, deontología, derecho disciplinario, ética profesional, tribunales de ética.

\section{Abstract}

Objective: To describe the general characteristics of the ethical-professional disciplinary law in Colombia.

Methodology: A qualitative, documentary, descriptive and deductive historical study was carried out, based on the disciplinary regimes of fourteen professional codes of ethics of some of the most traditional professions in the country that have been regulated by the Colombian legislator.

Findings: An approach to the concept of ethical-professional disciplinary law, its legal nature, its substantial differences with disciplinary law, its relationship with the Colombian system of regulatory sources, and a description of its main legal-procedural institutions was achieved.

Conclusions: The enormous influence that ethical-professional disciplinary law receives from disciplinary law and criminal law was verified, and a disparity was evident between the disciplinary regimes of the professional codes of ethics analyzed, since some stand out for their procedural guarantees, while those issued prior to the 1991 Constitution are lagging behind, so it is urgent to update them to bring them in line with the constitutional and conventional standards that govern the matter.

Key words: Deontology, disciplinary law, ethics courts, professional associations, professional councils, professional ethics.

\section{Resumo}

Objetivo: Descrever as características gerais do direito disciplinar ético-profissional da Colômbia.

Metodologia: Foi realizado um estudo histórico qualitativo, documental, descritivo e dedutivo, com base nos regimes disciplinares de quatorze códigos de ética profissional de algumas das profissões mais tradicionais do país, regulamentadas pelo legislador colombiano.

Constatações: Foi alcançada uma abordagem ao conceito de direito disciplinar ético-profissional, sua natureza jurídica, suas diferenças substanciais com o direito disciplinar, sua relação com o sistema colombiano de fontes reguladoras e uma descrição de suas principais instituições processuais-legais.

Conclusões: Verificou-se a enorme influência que o direito disciplinar ético-profissional recebe do direito disciplinar e do direito penal, e ficou evidente uma disparidade entre os regimes disciplinares dos códigos de ética 
profissional analisados, uma vez que alguns se destacam por suas garantias processuais, enquanto aqueles emitidos antes da Constituição de 1991 estão atrasados, é urgente atualizá-los para adequá-los aos padrões constitucionais e convencionais que governam o assunto.

Palavras-chave: Associações profissionais, conselhos profissionais, deontologia, direito disciplinar, ética profissional, tribunais de ética.

\section{INTRODUCCIÓN}

Aunque se registraron algunos antecedentes del derecho de libertad de escogencia de profesión, arte u oficio en la Constitución Provincial de Cundinamarca de $1811^{1} \mathrm{y}$ en la Constitución Política de la Nueva Granada de 1832², fue a partir de la expedición de la Constitución de 1886 que se evidenció la sentida necesidad de empezar a regular determinadas profesiones liberales y exigir títulos de idoneidad profesional, en función de nuestra tradición educativa.

Es así que en su artículo 44 permitía a toda persona "abrazar cualquier oficio u ocupación honesta sin necesidad de pertenecer a gremio de maestros o doctores", para lo cual, además de imponer a las autoridades el deber de inspeccionar a las industrias y profesiones en lo relativo a la moralidad, la seguridad y la salubridad públicas, facultaba a la ley para exigir títulos e idoneidad en el ejercicio de las profesiones médicas y de sus auxiliares; de modo que para las demás profesiones tradicionales en Colombia no era imperativa tal exigencia, pero con el pasar del tiempo se hizo obligatoria.

De esta manera, la siguiente profesión de vieja data en ser incorporada a este esquema de restricción fue la abogacía, esto conforme al Acto Legislativo 01 de 1918 que sustituyó el artículo 44 de la Constitución de 1886, norma que a su vez fue sustituida por el Acto Legislativo 01 de 1921. A esta le siguió la ingeniería, tal como lo dispuso el Acto Legislativo 02 de 1931, reiterado por el Acto Legislativo 01 de 1932.

En la gran reforma constitucional del Acto Legislativo 01 de 1936, esta disposición fue nuevamente objeto de modificación al dejar abierta (en su artículo 15) la posibilidad genérica de exigir por ley títulos de idoneidad y reglamentar el ejercicio de las profesiones, de tal suerte que el artículo paso de ser enunciativo en las profesiones, a disponer que en esa labor se impondría el criterio del legislador en cuanto a las profesiones que debían ser reglamentadas.

Sin embargo, la reforma concretada con el artículo 26 de la Constitución de 1991 representó un salto cualitativo en comparación con las normas antecesoras,

\footnotetext{
1 Título XIV. Disposiciones Generales. Artículo 1, numeral 2.
}

2 Artículo 195. 
pues introdujo innovaciones tales como: (i) la restricción del libre ejercicio profesional cuando este implique un riesgo social; (ii) la posibilidad de que las profesiones legalmente reconocidas se organicen en colegios, cuya estructura interna y funcionamiento deberán ser democráticos; y (iii) la facultad que se le otorga al legislador para asignarles a los colegios funciones públicas con los debidos controles. Estos dos últimos aspectos denotan la influencia que allí tuvo la Constitución española de 1978, por cuanto su artículo 36 incluye similares prerrogativas.

Estos mandatos constitucionales se tradujeron en la expedición de leyes y decretos desde principios del siglo XX, en los que se planteaba la necesidad de obtención y reconocimiento de los títulos universitarios para la autorización del ejercicio de las profesiones referidas por el constituyente. Tal cometido que se concretaba con la expedición de licencias por parte de las Juntas Centrales o Seccionales en el caso de las profesiones del área de la salud, que en algunos eventos contaban con facultades para la cancelación de las licencias con base en criterios discrecionales; ; mientras que en el caso de la ingeniería estas funciones las ejercía su Consejo Profesional ${ }^{4}$, en contraste con la abogacía puesto que tales atribuciones se compartían entre algunos ministerios, los tribunales y las altas cortes ${ }^{5}$.

Sucesivamente, la década de los cincuenta vio surgir la primera generación de Códigos de Ética Profesional con rango normativo, iniciada con la expedición del Código Deontológico de la Medicina, acogido por el Gobierno nacional a través del Decreto 2831 de 1954. Esta se convirtió en tendencia en las décadas subsiguientes para varias profesiones que también promulgaron sus códigos de ética profesional, elaborados por el Gobierno nacional a través de sus ministerios mediante decreto, resolución o acuerdo, en coordinación con los Consejos Profesionales, a los que en sus leyes de creación se les asignaba expresamente esa facultad, salvo contadas excepciones.

En el proceso de reglamentación legal de las profesiones, el legislador ha empleado una técnica similar en la mayoría de los casos, por cuanto estas leyes inician con el reconocimiento de la profesión, sus campos de acción, los títulos necesarios para su ejercicio y las condiciones de validez de estos; luego, referencian la regla de proporcionalidad para los profesionales extranjeros en las empresas públicas y

3 Cf. Ley 71 de 1890; Ley 12 de 1905; Decreto 592 de 1905; Ley 83 de 1914; Ley 37 de 1912; Ley 67 de 1920; Ley 85 de 1922; Ley 35 de 1929; Decreto 1099 de 1930; Decreto 1624 de 1930; Decreto 1672 de 1930; Decreto 62 de 1931; Decreto 507 de 1931; Decreto 393 de 1932; Decreto 986 de 1932; Ley 67 de 1935; Ley 48 de 1936 artículo 13; Decreto 2736 de 1936, entre otras disposiciones.

4 Cf. Leyes 67 de 1935 y 94 de 1937; Decreto 1782 de 1954, entre otras.

5 Cf. Ley 12 de 1905; Decreto 1165 de 1905; Leyes 40 de 1907, 37 de 1912, 62 de 1928, 21 de 1931, 67 de 1935, 69 de 1945, entre otras disposiciones. 
privadas, y proceden a la creación de un Consejo Profesional a nivel nacional con sede en Bogotá, y en algunas ocasiones a nivel seccional, conformados por los ministros relacionados con el ámbito de la profesión, las autoridades locales, los decanos de las facultades de las universidades que expiden títulos en la profesión y los representantes de las asociaciones de profesionales, entre otros ${ }^{6}$.

Igual acontece con las funciones que se atribuyen a estos Consejos, dado que se concentran en: (i) el registro y la expedición de una matrícula profesional; (ii) la concesión de permisos temporales para extranjeros; (iii) la denuncia ante las autoridades competentes por el ejercicio ilegal de la profesión; (iv) servir de cuerpo consultivo al Gobierno nacional en los ámbitos de su competencia, otorgando el mismo estatus a sus principales asociaciones de profesionales creadas previamente para la defensa de sus intereses de gremio; (v) la expedición de un código de ética de la profesión por su cuenta o en coordinación con el Gobierno nacional, o en su defecto la presentación de una propuesta de proyecto de ley al Congreso en ese sentido por intermedio de algún ministerio; y (vi) la cancelación de la matrícula profesional por violación al código de ética profesional.

No obstante, la expedición de la Constitución de 1991 trajo consigo un cambio de paradigma al respecto, pues de acuerdo con el numeral 2 de su artículo 150 solo el legislador está facultado para expedir Códigos, prohibición que se extiende a los casos de las facultades extraordinarias del numeral 10 del mismo artículo. Esta facultad ha sido contrastada en múltiples ocasiones por la jurisprudencia de la Corte Constitucional para salvaguardar el principio de reserva legal que debe imperar en la reglamentación del ejercicio de las profesiones y la expedición de códigos deontológicos?

Tal circunstancia ha hecho posible que los códigos de ética de segunda generación, proferidos en su gran mayoría durante el siglo XXI, se aproximen con sumo rigor a los estándares elaborados por la Corte Constitucional, ya que se consagran a través de una ley de la república que generalmente incluye: (i) la definición, campo de acción, requisitos y títulos e idoneidad necesarios para el ejercicio de la profesión; (ii) los organismos encargados de su autorización e inspección, vigilancia y control, señalando sus funciones específicas; (iii) los catálogos de principios y conductas éticas detalladas, relacionadas exclusivamente con el ejercicio de la profesión; (iv) un régimen que define con precisión las faltas, sanciones, criterios de graduación,

6 Cf. Leyes 9 de 1974, 53 de 1975, 18 de 1976, 53 de 1977, 60 de 1981, 58 de 1983, 20 y 22 de 1984, 51 de 1986, 28 y 33 de 1989, entre otras disposiciones.

7 Cf. Sentencias C-606 de 1992, C-012 de 2000, C-340 de 2006, C-884 de 2007, C-385 de 2015, C-274 de 2016. 
atenuantes y agravantes, entre otros; y (v) el procedimiento disciplinario para hacer efectivo su régimen sancionatorio, con sus respectivas etapas procesales, recursos, nulidades y prescripciones, entre otros aspectos ${ }^{8}$.

En ese ámbito, se localiza el derecho disciplinario ético-profesional, por lo que el presente artículo pretende aproximarse a su naturaleza jurídica, sus diferencias sustanciales con el derecho disciplinario y su relación con el sistema colombiano de fuentes normativas, con la finalidad de construir una definición correspondiente. Después, se caracterizará la estructura que suele seguir el procedimiento disciplinario ético-profesional.

\section{NATURALEZA JURÍDICA DEL DERECHO DISCIPLINARIO ÉTICO PROFESIONAL}

\section{Aspectos jurisprudenciales}

De manera reiterada, la Corte Suprema de Justicia y la Corte Constitucional han sostenido que el derecho sancionador del Estado en ejercicio del ius puniendi comprende como género por lo menos cinco especies, a saber: (i) el derecho penal delictivo; (ii) el derecho de punición por indignidad política o impeachment; (iii) el derecho contravencional; (iv) el derecho disciplinario; y (v) el derecho correccional. Estas tres últimas son correspondientes al denominado derecho administrativo sancionador ${ }^{9}$, el cual fue concebido como un instrumento para la realización de los fines que la Constitución le atribuye a la administración, con la asignación de competencias que la habilitan para imponer a sus funcionarios y a los particulares el acatamiento de una disciplina, incluso por medios punitivos, distinguiendo en esa órbita sancionatoria entre aquella que opera frente a sus propios servidores a través del derecho disciplinario y la que se ejerce frente a la generalidad de los administrados, denominada derecho correccional ${ }^{10}$.

Profundizando en lo anterior, se tiene que la Corte Constitucional, en la Sentencia C-597 de 1996, se refirió al "derecho disciplinario ético-profesional" que se expresa a través de las sanciones que el Estado impone con fundamento en la facultad de

8 Cf. Leyes 266 de 1996, 435 de 1998, 576 de 2000, 650 de 2001, 841 y 842 de 2003, 911 de 2004, 1090 de 2006, 1123 de 2007, 1193, 1240 y 1264 de 2008, 1409 de 2010, 1768 de 2015, 1796 de 2016, entre otras disposiciones.

9 Cf. Corte Suprema de Justicia. Sentencia 51 de 1983 (M.P. Manuel Gaona Cruz; abril 14 de 1983); Corte Constitucional: Sentencias C-214 de 1994, C-597 de 1996, C-948 de 2002, C-406 de 2004, C-762 de 2009, C-899 de 2011. Cfr. Consejo de Estado. Sala de Consulta y Servicio Civil, radicación número: 11001-03-06-000-2017-00079-00(2340).

10 Cf. Corte Constitucional de Colombia. Sentencia C-597 de 1996. 
inspección y vigilancia de las profesiones, derivada del artículo 26 de la Constitución Política, en tanto que en la Sentencia C-899 de 2011 consideró la existencia de un "derecho disciplinario frente a las profesiones", que parte de la regulación que el legislador expide para el ejercicio de una determinada profesión u oficio, con el fin de proteger a la sociedad del riesgo que aquella puede representar, y que a su vez justifica la necesidad de sancionar su ejercicio indebido o irresponsable a través del reproche del desconocimiento de las normas de conducta que cada actividad impone, "pues se exige una serie de comportamientos éticos que le den seguridad, confianza y rectitud al ejercicio de la profesión"11 para salvaguardar el interés general inmerso en su ejercicio.

Para tales cometidos, la Corte aseveró en esa providencia, con fundamento en la Sentencia C-530 de 2000, que le corresponde al legislador determinar la composición y señalar las funciones de los órganos encargados del control disciplinario "para asegurar que el ejercicio de la respectiva profesión se cumpla dentro de ciertos parámetros éticos y de eficiencia, eficacia y responsabilidad, acordes con el interés general que demanda la prevención de los aludidos riesgos", aclarando que la competencia para imponer dichas sanciones puede recaer en un órgano estatal, tal como sucede con los abogados y el Consejo Superior de la Judicatura y sus Consejos Seccionales ${ }^{12}$, o puede recaer en los particulares a los que el legislador en ejercicio de su libertad de configuración les atribuye dicha competencia, siendo este el caso de los tribunales de ética ${ }^{13}$.

En este último caso, el Alto Tribunal concluyó que la asignación de esa facultad sancionatoria correccional a los particulares ha llevado a que doctrinariamente se refiera la existencia de un "derecho disciplinario delegado", en la medida en que el Estado les asigna a unos sujetos cualificados el ejercicio de una típica función pública, como es la aplicación del derecho correccional a quienes ejercen una profesión u oficio.

Del mismo modo, al Consejo de Estado también le ha correspondido disertar acerca de la naturaleza jurídica de estas atribuciones, en tanto que la Sección Primera de la Sala de lo Contencioso Administrativo, en Sentencia del 26 de julio de $2018^{14}$, analizó si el Consejo Profesional Nacional de Ingeniería - Copnia incurrió en nulidad

11 Cf. Sentencia C-190 de 1996, M.P. Hernando Herrera Vergara, citada en la Sentencia C-899 de 2011.

12 Cf. Ley 1123 de 2007.

13 Cf. Leyes 23 de 1981, 35 de 1989, 650 de 2001, 266 de 1996, 911 de 2004, entre otras disposiciones.

14 Radicación número: 25000-23-24-000-2011-00409-01. Actor: Mariano Pinilla Poveda. Demandado: Consejo Profesional Nacional de Ingeniería-Copnia. Referencia: Nulidad y restablecimiento del derecho-apelación. 
por falta de competencia, violación de los principios non bis in ídem y cosa juzgada al sancionar a un curador urbano por las fallas cometidas en el ejercicio de su profesión, cuando también la Procuraduría General de la Nación le había adelantado una investigación disciplinaria en la cual fue absuelto, para concluir que una misma conducta puede dar lugar a sanciones de diversas categorías sin que por esto se vulnere el derecho al debido proceso, partiendo de la base de la existencia de un "derecho ético".

Nótese que los anteriores pronunciamientos coinciden en desmarcar del derecho disciplinario tradicional aquel derecho correccional, ético, profesional, o disciplinario delegado, que se ejerce para que los órganos que el legislador ha dispuesto para ese fin sancionen a los profesionales por las conductas que atentan contra los preceptos éticos de su profesión. Esto permite referirse en lo sucesivo a esta función o rama del conocimiento jurídico como un derecho disciplinario ético-profesional, tal como se empezó a rotular desde la expedición de la Ley 23 de 1981.

Desde el punto de vista funcional, es posible ubicar el derecho disciplinario ético-profesional como una manifestación de la función de control depositada mayoritariamente en los Consejos Profesionales y los Tribunales de Ética, en razón a que representa la potestad sancionatoria del Estado que les asegura eficacia a sus códigos de ética profesional mediante la adopción de correctivos que se traducen en sanciones por su inobservancia ${ }^{15}$, donde juegan un papel esencial las garantías constitucionales relacionadas con el debido proceso.

\section{Diferencias sustanciales con el derecho disciplinario}

Como se ha expresado en múltiples oportunidades, el derecho disciplinario tiene su fundamento en la relación especial de sujeción que existe entre el servidor público y el Estado, o el particular que ejerce materialmente una función pública, que a su vez permite la imposición de deberes, prohibiciones, inhabilidades e incompatibilidades para que el Estado cumpla en forma adecuada las funciones asignadas por la Constitución y la ley ${ }^{16}$. Ese vínculo es inexistente en el derecho disciplinario ético-profesional, por cuanto la autorización e inspección, vigilancia y control del Estado para el ejercicio de una profesión no genera vínculo laboral o contractual alguno entre el profesional y el Estado.

Cosa distinta ocurre cuando ese profesional trabaja para la administración pública, pues aunque en ese ámbito se establece una relación especial de sujeción con el

15 Cf. Corte Constitucional de Colombia. Sentencia C-246 de 2019.

16 Cf. Corte Constitucional de Colombia. Sentencia C-899 de 2011, entre otras disposiciones. 
Estado que le obliga a seguir las normas que la regulan, cuando aquel ejecuta el acto profesional característico en el que emite un juicio relacionado con su profesión, debe tomar la decisión de acuerdo con su código de ética profesional.

En este caso, es posible que bajo un mismo supuesto se quebranten las normas que regulan cada relación, y que por ende concurran simultáneamente la potestad disciplinaria y la acción disciplinaria ético-profesional, atendiendo a su carácter autónomo e independiente que desvirtúa la posibilidad de que la Procuraduría General de la Nación, como titular de la primera ${ }^{17}$, haga uso de su poder preferente disciplinario para ejercer la segunda en nombre de algún Consejo Profesional o Tribunal de Ética, tal como se infiere de la sentencia proferida por la Sección Primera de la Sala de lo Contencioso Administrativo del Consejo de Estado el 26 de julio de 201818.

Al profundizar aún más en lo anterior, las consecuencias jurídicas de la aplicación de la acción disciplinaria y de la acción disciplinaria ético-profesional varían ostensiblemente en uno y otro caso, pues mientras que en la primera las sanciones a imponer se circunscriben a la afectación del ejercicio de una función pública específica, usualmente concretadas en suspensión del cargo o destitución e inhabilidad general ${ }^{19}$, en la segunda los efectos jurídicos de las sanciones son de mayor alcance, en la medida en que afectan el ejercicio de una profesión en todos sus ámbitos, generalmente a través de la amonestación, o la suspensión temporal o cancelación de la matrícula profesional, con lo que se prevé en algunos casos la posibilidad de rehabilitación bajo el cumplimiento de ciertas condiciones.

En todo caso, se advierte que estas sanciones no se deben confundir con la potestad de los jueces penales para imponer, a título de pena privativa de otros derechos, la inhabilitación para el ejercicio de una profesión, arte, oficio, industria o comercio, que debe imputarse por el mismo tiempo de la pena de prisión impuesta sin exceder los límites señalados en el artículo 51 de la Ley 599 de 2000, "siempre que la infracción se cometa con abuso del ejercicio de cualquiera de las mencionadas actividades, medie relación de causalidad entre el delito y la profesión o contravenga las obligaciones que de su ejercicio se deriven"20. En este marco, una vez en firme la sentencia que impone esta pena, le corresponde al juez proceder a comunicarla a la respectiva Cámara de Comercio para su inclusión en el Registro Único Empresarial - RUES, a la Dirección de

17 Constitución Política de Colombia. Artículo 277, numeral 6.

18 Radicación número: 25000-23-24-000-2011-00409-01. Actor: Mariano Pinilla Poveda. Demandado: Consejo Profesional Nacional de Ingeniería-Copnia. Referencia: Nulidad y restablecimiento del derecho-apelación.

19 Cf. Ley 734 de 2002, artículos 44 y siguientes; Ley 1952 de 2019, artículos 48 y siguientes.

20 Código Penal colombiano. Ley 599 de 2000. Artículo 46, modificado por el artículo 3 de la Ley 1762 de 2015. 
Impuestos y Aduanas Nacionales - DIAN y a las demás autoridades encargadas del registro de la profesión, comercio, arte u oficio del condenado, según corresponda²1.

De otra parte, también es imperativo distinguir que en el derecho disciplinario se han concebido otros regímenes diferenciados que responden a la especificidad de la función pública que ejercen determinados servidores públicos o particulares, por lo cual no se les puede sancionar por cualquier tipo de falta disciplinaria genérica, sino únicamente frente a aquellas relacionadas con las funciones especiales que ejercen y cuya comisión afecte directamente el servicio público que les fue encomendado22; tal es el caso de las Fuerzas Militares ${ }^{23}$, la Policía Nacional24, los congresistas ${ }^{25}$, los docentes ${ }^{26}$, los bomberos ${ }^{27}$, los curadores urbanos ${ }^{28}$ y los registradores de instrumentos públicos ${ }^{29}$, entre otros.

La regulación legal de estas funciones especiales de ningún modo corresponde propiamente a un acto de reconocimiento de una profesión y de sometimiento al régimen de autorización e inspección, vigilancia y control estatal, de conformidad con el artículo 26 de la Carta Política. Máxime cuando el ejercicio de tales funciones especiales presenta como elemento en común la existencia de una relación especial o material de sujeción con el Estado, que sustrae a quienes las ejercen de la órbita del derecho disciplinario ético-profesional.

A fin de ilustrar este argumento, la Corte Constitucional en la Sentencia C-399 de 1999 declaró la inexequibilidad de varias disposiciones del Decreto 960 de 1970, que instaban a los notarios a asociarse a través de un colegio profesional. Para ello, partió de la base de que el notariado no es una profesión legalmente reconocida en los términos del artículo 26 de la Constitución, sino una actividad que en virtud de su importancia social ha sido regulada por el legislador, con el fin de llevar un control necesario sobre unas atribuciones que implican necesariamente un riesgo

\section{Ibidem.}

22 Cf. Corte Constitucional de Colombia. Sentencia C-053 de 2018, entre otras disposiciones.

23 Cf. Decreto 1797 de 2000, Ley 836 de 2003, Ley 1862 de 2017, Decreto 697 de 2019, entre otras disposiciones.

24 Cf. Ley 62 de 1993, Decreto 2584 de 1993, Ley 180 de 1995, Ley 578 de 2000, Decreto 1798 de 2000, Ley 1015 de 2006, entre otras disposiciones.

25 Cf. Ley 5 de 1992, Ley 668 de 2001 y Ley 1828 de 2017.

26 Cf. Ley 2 de 1937, Ley 43 de 1945, Ley 64 de 1947, Decreto 1135 de 1952, Ley 20 de 1960, Ley 14 de 1971, Ley 8 de 1979, Decreto 2277 de 1979, Decreto 2480 de 1986, Decreto 1278 de 2002, Ley 734 de 2002, entre otras disposiciones.

27 Cf. Ley 322 de 1996, Decreto 953 de 1997, Ley 1575 de 2012, entre otras disposiciones.

28 Cf. Ley 1796 de 2016.

29 Cf. Ley 1579 de 2012, Decreto 2723 de 2014, entre otras disposiciones. 
social. Así, deja a criterio de los notarios, en virtud del libre ejercicio de sus posibilidades constitucionales y legales, los términos y las razones de su organización asociativa correspondiente.

Aún más, en relación con la ilicitud sustancial como elemento característico de la falta disciplinaria ${ }^{30}$, la inexistencia de una relación especial de sujeción en el derecho disciplinario ético-profesional no permite ubicar tal elemento en la estructura de la falta disciplinaria ético-profesional. El incumplimiento del deber funcional de manera injustificada, entendido como la inobservancia de alguna función cuyo titular sea el sujeto activo, el servidor público o un particular disciplinable, precisamente se deriva de la relación de sujeción especial y de la carga pública impuesta a quienes desempeñan funciones estatales. Por eso además su conducta debe ser sustancialmente antijurídica, es decir que conlleve la afectación de cualquier principio de la función administrativa contenido en el artículo 209 de la Constitución; y si el deber incumplido no es funcional, el Estado no puede imponer sanciones disciplinarias por conductas que formen parte del fuero interno de sus agentes ${ }^{31}$.

En cuanto a la antijuridicidad material, hay que partir de la base de que los bienes jurídicos son todas aquellas circunstancias o finalidades necesarias para el libre desarrollo del individuo y la realización de sus derechos fundamentales, de tal suerte que el papel del derecho consiste en identificarlas, reconocerlas y protegerlas ${ }^{32}$. Tal postulado que nos lleva a inferir que la protección de los bienes jurídicos varia ostensiblemente en el derecho disciplinario y en el derecho disciplinario ético-profesional, en razón a que en el primero de ellos, el bien jurídico tutelado por excelencia es el correcto ejercicio de la función pública, o el cumplimiento del deber funcional ${ }^{33}$, sin que esto quiera decir que allí no se puedan identificar otros bienes de naturaleza especial34; mientras que en el derecho disciplinario ético-profesional, el principal bien jurídico tutelado lo será el adecuado ejercicio de la profesión que el Estado autoriza, inspecciona, vigila y controla para proteger a la sociedad del riesgo que aquella pueda generar.

30 Cf. Ley 734 de 2002, artículo 5; Ley 1952 de 2019, artículo 9.

31 José Adolfo González. DERECHO DIScIPLINARIO Y BIEN JURíDIco. Bogotá: Procuraduría General de la Nación - Instituto de Estudios del Ministerio Público. (2016). Págs. 41-44.

32 Ibidem, pp. 49 a 53.

33 Carlos Mario Isaza. TEORíA GENERAL DEL DERECHO DISCIPLINARIO. ASPECTOS HISTÓRICOS, SUSTANCIALES Y PROCESALES. 2. ${ }^{a}$ ed. Bogotá: Editorial Temis. (2009). Págs. 126-131.

34 José Adolfo González, supra, nota 32, pág. 56 a 66. 


\section{El derecho disciplinario ético-profesional y el sistema de fuentes normativas}

En efecto, el derecho disciplinario ético-profesional se nutre del sistema de fuentes concebido en el ordenamiento jurídico colombiano, el cual ha sido ampliamente delimitado por la Corte Constitucional con fundamento en el artículo 230 de la Carta de 1991. Se aclara que las fuentes del derecho están constitucionalmente clasificadas en dos grupos de diferente jerarquía, así: (i) una fuente obligatoria, como es el "imperio de la ley", entendiendo la ley en su sentido material como norma vinculante de manera general y no la ley en sentido formal expedida por el órgano legislativo, por cuanto la primera de las normas es la Constitución; y (ii) las fuentes auxiliares, que comprenden la equidad, la jurisprudencia, los principios generales del derecho y la doctrina ${ }^{35}$, tal como se encuentran reiteradas en las Leyes 650 de 20016, 911 de $2004^{37}, 1193$ de $2008^{38}$ y 1240 de $2008^{39}$, que las asumen como criterios auxiliares en el juzgamiento.

Sin embargo, la Corte Constitucional ha considerado, con fundamento en el artículo 243 superior, que la jurisprudencia constitucional es fuente obligatoria de derecho, por cuanto sus sentencias tienen el valor de cosa juzgada constitucional y son de obligatorio cumplimiento para todas las autoridades y los particulares. Precisa que su parte resolutiva goza de cosa juzgada explícita y que algunas consideraciones de la parte motiva que guarden unidad y relación directa con la decisión gozan de cosa juzgada implícita, que también es obligatoria y debe ser observada por las autoridades ya que corrigen la jurisprudencia. Esto se conoce como el carácter vinculante del precedente judicial, que incluso ha llevado a una reinterpretación del concepto de ley, como elemento normativo del delito de prevaricato en el orden jurídico colombiano ${ }^{40}$.

Pues bien, la Corte Constitucional ha señalado que, por regla general, los principios del derecho penal como forma paradigmática de control de la potestad punitiva se aplican mutatis mutandi con ciertos matices a todas las formas de actividad sancionadora del Estado, como es el derecho disciplinario ético-profesional, toda vez que consagran garantías sustanciales y procesales a favor de la persona investigada para proteger sus derechos fundamentales y controlar la potestad sancionadora del

35 Cf. Sentencia T-704 de 2012.

36 Artículo 72.

37 Artículo 42, numeral 9.

38 Artículo 10, numeral 9.

39 Artículo 22, literal h).

40 Cf. Sentencias C-104 de 1993, C-131 de 1993, C-037 de 1996, C-836 de 2001, C-539 de 2011 , entre otras disposiciones. 
Estado. Por tal razón, la Constitución señala que el debido proceso se debe aplicar a toda clase de actuaciones judiciales y administrativas, cuyos principios se deben aplicar en estas áreas pero pueden operar con una cierta flexibilidad en relación con el derecho penal, tal como lo refirió en la Sentencia C-597 de 1996.

A esta rama del derecho también se integran los tratados y convenios internacionales, ratificados por el Congreso de la República, que reconocen los derechos humanos y prohíben su limitación en los estados de excepción, los cuales prevalecen en el orden interno según lo determina el artículo 93 de la Constitución de 1991, en el que es posible inferir que el derecho disciplinario ético-profesional se debe alimentar de los principios universales relacionados con el debido proceso.

Entre los principales instrumentos internacionales que sobresalen al respecto, se destaca el artículo 10 de la Declaración Universal de Derechos Humanos de 1948, que establece el derecho de toda persona a ser juzgada por un tribunal independiente e imparcial, y el artículo 11 referente a la presunción de inocencia y los principios de legalidad e irretroactividad de la ley penal, siendo estas unas garantías procesales que se desarrollan con mayor rigor en los artículos 14 y 15 del Pacto Internacional de Derechos Civiles y Políticos de las Naciones Unidas de $1966^{41}$.

En el plano regional, es importante tener en cuenta que el Estado colombiano es parte de la Convención Americana sobre Derechos Humanos, o "Pacto de San José de Costa Rica", adoptada por la Organización de Estados Americanos (OEA) en 1969 y que a su vez fue aprobada por el Congreso de la República de Colombia con la Ley 16 de 1972, es decir que hace parte del bloque de constitucionalidad y prevalece en el ordenamiento jurídico colombiano, dada su intrínseca relación con los derechos humanos.

De tal suerte, el derecho disciplinario ético-profesional y las actuaciones procesales que se surtan en su desarrollo se encuentran sujetas al control de convencionalidad difuso. Es decir que las autoridades administrativas y judiciales encargadas de la investigación y sanción de las conductas contrarias a la ética de una profesión reconocida por el legislador colombiano deben dar aplicación a los instrumentos del corpus iuris interamericano relacionados con esta función de control, entre ellos el artículo 8 de la Convención que consagra las garantías judiciales, el artículo 9 que hace alusión al principio de legalidad y retroactividad, los artículos 1.1 y 24 sobre el principio de no discriminación e igualdad ante la ley, y las sentencias que la Corte Interamericana de Derechos Humanos haya proferido sobre el particular. 


\section{Definición y objeto del derecho disciplinario ético-profesional}

Con fundamento en los elementos normativos y jurisprudenciales anteriormente esbozados, es posible aproximarse a una definición del derecho disciplinario ético-profesional, el cual podría describirse como el conjunto de normas e instituciones derivadas del ius puniendi estatal y el derecho administrativo sancionador que propenden al adecuado ejercicio de una profesión reglamentada por el legislador colombiano. Esto con el fin de proteger a la sociedad de los riesgos que su práctica pueda implicar, a través de la imposición de modelos de conducta de carácter deontológico consagrados en una ley de la república a manera de códigos de ética profesional, contentivos de un mínimo de principios, derechos, deberes y prohibiciones, que a su vez disponen de un régimen sancionatorio y un procedimiento disciplinario específico para castigar al profesional que con su proceder los infringe, previo cumplimiento de todas las garantías constitucionales y convencionales relacionadas con el derecho fundamental al debido proceso.

La naturaleza jurídica de esta rama del derecho es pública ${ }^{42}$, ya que se manifiesta como una función de carácter administrativo y excepcionalmente judicial para el caso de la abogacía, que suele ser ejercida por los Consejos Profesionales, los Tribunales de Ética Profesional, el Consejo Superior de la Judicatura y la Comisión Nacional de Disciplina Judicial ${ }^{43}$, quienes a su vez son los titulares de la acción disciplinaria ético-profesional por mandato constitucional o legal del Estado colombiano como titular del ius puniendi o la potestad de sancionar. Esta última es posible delegarla en los colegios profesionales bajo la satisfacción de determinados requisitos constitucionales y legales.

En el ámbito de los modelos de autorización e inspección, vigilancia y control concebidos por el legislador para el ejercicio de una profesión en particular, esta acción encuentra su lugar en la función de control. Esto se debe a que representa la imposición de un correctivo cuyo objeto es dirigir o reorientar la conducta del profesional hacia el cumplimiento de unos imperativos ético-profesionales previamente establecidos ${ }^{44}$, sin perder de vista que también cumple una función pedagógica y preventiva ${ }^{45}$ en la medida en que busca persuadir y disuadir a los demás profesionales para que no incurran en la violación de esos preceptos.

\footnotetext{
42 Cf. Ley 1264 de 2008, artículo 62.

43 Cf. Acto Legislativo 02 de 2015.

44 Cf. Corte Constitucional de Colombia. Sentencia C-246 de 2019.

45 Cf. Ley 1123 de 2007. Artículo 11.
} 
Como disciplina jurídica autónoma de orden doméstico ${ }^{46}$, el derecho disciplinario ético-profesional se nutre de las fuentes generales del derecho definidas por la Constitución Política de Colombia y la jurisprudencia de la Corte Constitucional, con el objetivo primordial de establecer, bajo criterios de razonabilidad y proporcionalidad, la verdad real en cada proceso disciplinario ético-profesional que se surte, a través de la aplicación de una serie de principios y etapas específicas.

\section{ESTRUCTURA DEL PROCESO DISCIPLINARIO ÉTICO-PROFESIONAL}

Para ahondar en la caracterización del derecho disciplinario ético-profesional, se determinarán los rasgos preponderantes de sus instituciones jurídico-procesales mediante el análisis de catorce códigos deontológicos vigentes de algunas de las profesiones más tradicionales, a saber: (i) medicina, Ley 23 de 1981; (ii) odontología, Ley 35 de 1989; (iii) contaduría, Ley 43 de 1990; (iv) enfermería, Leyes 266 de 1996 y 911 de 2004; (v) arquitectura, Leyes 435 de 1998 y 1768 de 2015; (vi) medicina veterinaria y zootecnia, Ley 576 de 2000; (vii) optometría, Ley 650 de 2001; (viii) bacteriología, Leyes 841 de 2003 y 1193 de 2008; (ix) ingeniería, Leyes 842 de 2003 y 1796 de 2016; (x) psicología, Ley 1090 de 2006; (xi) abogado, Ley 1123 de 2007; (xii) terapia respiratoria, Ley 1240 de 2008; (xiii) técnicos electricistas, Ley 1264 de 2008; y (xiv) archivistas, Ley 1409 de 2010.

\section{Definición y elementos de la falta disciplinaria ético-profesional}

Algunos regímenes disciplinarios de los códigos de ética profesional anteriormente mencionados han sido categóricos al determinar qué es la falta disciplinaria y cuáles son los elementos que la conforman. Un contexto en el que conciben la falta que promueve la acción disciplinaria ético-profesional como el incumplimiento de los deberes o prohibiciones y cualquier violación del régimen de inhabilidades e

46 Sobre la autonomía de la acción disciplinaria ético-profesional y el deber de ejercerla sin perjuicio de la acción penal, civil, contencioso-administrativa o la acción disciplinaria general, las siguientes normas han reivindicado expresamente tal autonomía: Ley 576 de 2000, artículo 130; Ley 911 de 2004, artículo 71; Ley 1090 de 2006, artículo 89; Ley 1123 de 2007, artículo 2; Ley 1193 de 2008, artículo 39; Ley 1240 de 2008, artículo 48; Ley 1264 de 2008, artículo 65; Ley 1409 de 2010, artículo 31. 
incompatibilidades consagradas en el código de ética de su respectiva profesión, encaminadas a su correcto ejercicio ${ }^{47}$.

Así mismo, otros ordenamientos jurídicos distinguen cuáles son las faltas que son susceptibles de sanción disciplinaria, y para ello señalan que se castiga todo acto u omisión intencional o culposa del profesional que implique: violación de las prohibiciones y deberes, incumplimiento de las obligaciones, ejecución de actividades incompatibles con el decoro que exige el ejercicio de la profesión, o incurrir en actividades delictivas relacionadas con dicho ejercicio que se encuentren en las normas legales aplicables a este ${ }^{48}$.

De tal modo, varios de estos regímenes disciplinarios coinciden en que la configuración de la falta disciplinaria debe cumplir con las siguientes condiciones: (i) la conducta o el hecho debe haber sido cometido por un profesional debidamente matriculado en su Consejo o Colegio Profesional correspondiente; (ii) la conducta o el hecho debe ser doloso o culposo; (iii) el hecho o la conducta debe haber sido cometida en ejercicio de su profesión; (iv) la conducta debe ser apreciable objetivamente y procesalmente debe estar probada; y (v) la sanción disciplinaria debe ser la consecuencia lógica de un debido proceso, que se enmarque dentro de los postulados del artículo 29 de la Constitución y el régimen disciplinario establecido en la ley de la respectiva profesión ${ }^{49}$.

Aun así, la gran mayoría de estos regímenes disciplinarios concuerdan en excluir de la órbita de la acción disciplinaria ético-profesional a aquellas personas que ejercen ilegalmente una profesión objeto de reglamentación estatal, por cuanto se limitan a referir que ellas recibirán las sanciones que las leyes ordinarias fijan para estos $\operatorname{casos}^{50}$. De tal manera, la función de los Consejos, Colegios Profesionales y Tribunales de Ética se limita a poner en conocimiento estas situaciones ante las

47 Cf. Ley 842 de 2003, artículos 46 y 49; Ley 911 de 2004, artículo 42, numeral 1; Ley 1123 de 2007, artículos 17, 20 y 21; Ley 1193 de 2008, artículo 10, numeral 1; Ley 1264 de 2008, artículo 63; Ley 1409 de 2010, artículos 26 y 29; Ley 1768 de 2015, artículos 3 y 4.

48 Cf. Ley 842 de 2003, artículo 49; Ley 911 de 2004, artículo 42, numeral 1; Ley 1090 de 2006, artículo 60, numeral 1; Ley 1193 de 2008, artículo 10, numeral 1; Ley 1240 de 2008, artículo 22, literal a); Ley 1409 de 2010, artículo 29.

49 Cf. Ley 842 de 2003, artículo 50; Ley 1409 de 2010, artículo 30; Ley 1768 de 2015, artículo 5 .

50 La Ley 1801 de 2016 en su artículo 92 definió cuáles son los comportamientos relacionados con el cumplimiento de la normatividad que afectan la actividad económica y que por lo tanto no deben realizarse, observando que en el numeral 16 se incluyó el referente a "Desarrollar la actividad económica sin cumplir cualquiera de los requisitos establecidos en la normatividad vigente". 
autoridades competentes ${ }^{51}$, medida que encuentra su lógica en que la conducta de un profesional solo puede ser objeto de reproche deontológico cuando este ha sido reconocido por sus pares como tal y se ha comprometido a su cabal ejercicio.

Con base en todo lo anterior, es posible determinar entonces que la estructura de la falta disciplinaria ético-profesional consta de tres elementos esenciales: (i) la conducta, que debe ser cometida por un profesional debidamente matriculado y en ejercicio de su profesión, por acción u omisión; (ii) una apreciación objetiva de la conducta, en razón a que esta debe ser violatoria de deberes, prohibiciones, inhabilidades o incompatibilidades inherentes a la profesión, definidos en la ley que la regula; y (iii) la culpabilidad, pues solamente la conducta será objeto de reproche si es cometida a título de dolo o culpa. Complementariamente, la observancia de los principios constitucionales del debido proceso y la necesidad de la prueba le dan el sustento y la legitimidad adecuada a esta estructura.

Ahora bien, aunque solamente la Ley 1123 de 2007 en su artículo 4 alude a la antijuridicidad como uno de los principios rectores del Código Disciplinario del Abogado, es de anotar que el incumplimiento de los deberes, prohibiciones, inhabilidades o incompatibilidades contenidos en la ley que regula una profesión en particular supone no solo la violación de una norma de derecho, sino también la afectación del principal bien jurídico tutelado del derecho disciplinario ético-profesional, es decir, el adecuado ejercicio de la profesión que el Estado autoriza, inspecciona, vigila y controla para proteger a la sociedad del riesgo que aquella pueda generar. De tal manera, indirectamente sí es posible inferir la existencia de antijuridicidad dentro de la estructura de la falta disciplinaria ético-profesional.

Adicionalmente, como una muestra del influjo que el derecho penal ejerce sobre el derecho disciplinario ético-profesional, varios regímenes disciplinarios de los códigos de ética profesional disponen de causales de exclusión o justificación de la falta disciplinaria, las cuales se resumen así: (i) fuerza mayor o caso fortuito; (ii) estricto cumplimiento de un deber constitucional o legal de mayor importancia que el sacrificado; (iii) cumplimiento de orden legítima de autoridad competente emitida con las formalidades legales; (iv) salvar un derecho propio o ajeno al cual deba ceder el cumplimiento del deber en razón de la necesidad, adecuación, proporcionalidad y razonabilidad; (v) insuperable coacción ajena o miedo insuperable; (vi) convicción errada e invencible de que su conducta no constituye falta disciplinaria; y (vii) situación

51 Cf. Ley 266 de 1996, artículo 22; Ley 435 de 1998, artículos 12 y 13; Ley 841 de 2003, artículo 7, modificado por el artículo 6 de la Ley 1193 de 2008; Ley 842 de 2003, artículos 13 a 16 y 21; Ley 1090 de 2006, artículo 8; Ley 1264 de 2008, artículo 101; Ley 1409 de 2010, artículo 7 . 
de inimputabilidad, aclarando que no hay lugar a reconocerla cuando el sujeto investigado hubiere preordenado su comportamiento ${ }^{52}$.

No obstante, en consonancia con lo dispuesto en el artículo 29 de la Constitución Política, y en específico el principio de legalidad, se considera que estas causales son taxativas y excluyentes; es decir que solamente tienen plena aplicación en el régimen disciplinario ético-profesional que las consagra de manera precisa e inequívoca, y que no es posible acudir a la analogía para adaptar causales de exclusión de responsabilidad de otros ordenamientos jurídicos en procura de su aplicación, lo cual en todo caso no es óbice para que el operador disciplinario mutatis mutandi se valga de la dogmática penal o disciplinaria al momento de su valoración.

\section{Inicio de la acción disciplinaria ético-profesional y sujetos procesales}

Una de las expresiones inquisitivas del proceso disciplinario ético-profesional radica en la potestad que tienen las autoridades públicas titulares de esta acción para iniciar investigaciones de oficio, facultad que se ubica en todos los regímenes disciplinarios de los códigos de ética analizados. A esta prerrogativa se suman la presentación de la queja escrita y la solicitud escrita dirigida al respectivo Tribunal o Consejo por cualquier persona natural o entidad pública o privada, o informe de servidor público, como causales generalmente aceptadas para el inicio de la acción.

Simultáneamente, varios de estos regímenes consagran de forma expresa que para activar el ejercicio de esta acción es necesario que exista prueba sumaria del acto $u$ omisión presuntamente contrario a la ética profesional53, y que los anónimos no proceden salvo que suministren datos o medios de prueba que permitan encausar la investigación y cumplan con los requisitos mínimos establecidos en las normas vigentes ${ }^{54}$. Esta exigencia, conforme al artículo 81 de la Ley 962 de 2005, es imperativa para el ejercicio de toda acción jurisdiccional, penal, disciplinaria, fiscal o actuación de autoridad administrativa competente.

Aún más, en otros de estos regímenes se sanciona con multa la presentación de quejas falsas o temerarias ${ }^{55}$, o se precisa que si la denuncia permite establecer

52 Cf. Ley 842 de 2003, artículo 55; Ley 1123 de 2007, artículo 22; Ley 1409 de 2010, artículo 35; Ley 1768 de 2015, artículo 6.

53 Cf. Ley 23 de 1981, artículo 74; Ley 35 de 1989, artículo 70; Ley 576 de 2000, artículo 107; Ley 650 de 2001, artículo 73, literal b).

54 Cf. Ley 1123 de 2007, artículo 67; Ley 1768 de 2015, artículo 68, parágrafo.

55 Cf. Ley 1123 de 2007, artículo 69. 
la presunta violación de normas de carácter penal, civil o administrativo, de forma simultánea debe ponerse en conocimiento de la autoridad competente ${ }^{56}$. Este último mandato es análogamente exigible a todas las autoridades disciplinarias ético-profesionales, por cuanto se desprende del deber de denuncia de todo servidor público ${ }^{57}$ y de la obligación de remitir las actuaciones a las autoridades competentes cuando no se tiene competencia para su trámite y conocimiento ${ }^{58}$.

Entre tanto, en algunos regímenes disciplinarios se concibió la figura de la ratificación o ampliación de la queja ${ }^{59}$, diligencia que se surte de manera posterior a la recepción de la denuncia, con el fin de establecer si existe o no mérito para abrir investigación formal disciplinaria contra los presuntos infractores. Se subraya que cuando el quejoso es renuente a comparecer a la ratificación o ampliación de la queja y esta fuera necesaria para poder continuar la investigación preliminar, procede el archivo sumario de la queja por carecer de los elementos suficientes para establecer alguna clase de indicio en contra del profesional o su debida identificación o individualización.

En cuanto a los sujetos procesales que intervienen en el procedimiento disciplinario ético-profesional, se debe considerar, en primer lugar, al Estado como sujeto activo y titular de la acción disciplinaria ético-profesional, representado por el Consejo Profesional o Tribunal de Ética respectivo, quienes a su vez son los directores de la función disciplinaria responsables de ejercer esta acción en el marco constitucional y legal vigente, para cuyo trámite pueden obtener la asesoría jurídica que sea pertinente ${ }^{60}$. En segundo lugar, se debe considerar al profesional investigado como sujeto pasivo de la acción, quien se presume inocente mientras no se le declare responsable mediante fallo ejecutoriado de alguna de las faltas a la ética profesional consagradas en la ley que rige su profesión, para lo cual en el desarrollo del proceso puede ejercer sus derechos constitucionales directamente o a través de defensor de oficio o confianza.

Mayoritariamente, al quejoso no se le considera parte dentro del procedimiento disciplinario ético-profesional, pero en varios regímenes disciplinarios se le concede la facultad de aportar pruebas e interponer recurso contra las decisiones que pongan

56 Cf. Ley 23 de 1981, artículo 76; Ley 35 de 1989, artículo 72; Ley 576 de 2000, artículo 131; Ley 650 de 2001, artículo 76, parágrafo 2.

57 Cf. Ley 734 de 2002, artículo 34, numeral 24; Ley 1952 de 2019, artículo 38, numeral 25.

58 Ley 1437 de 2011, artículo 21, subrogado por el artículo 1 de la Ley 1755 de 2015.

59 Cf. Ley 43 de 1990, artículo 28, literal a); Ley 842 de 2003, artículo 61; Ley 1409 de 2010, artículo 40; Ley 1264 de 2008, artículo 71.

60 Cf. Ley 23 de 1981, artículo 77; Ley 35 de 1989, artículo 73; Ley 1264 de 2008, artículo 68. 
fin a la actuación ${ }^{61}$, con la subsecuente obligación de comunicarle las decisiones, subrayando que esta última prerrogativa también se le concede en algunos eventos al Ministerio Público ${ }^{62}$, cerrando de tajo la posibilidad de que estas atribuciones puedan ser ejercidas por cualquier tercero interesado.

\section{La indagación o averiguación preliminar}

Una vez se inicia la acción de manera oficiosa, o se recepciona la queja, o se ratifica la queja si hay lugar a ello, o se recibe el informe de servidor público, cuando el operador disciplinario tiene dudas acerca de la procedencia de la acción, los procedimientos disciplinarios ético-profesionales se caracterizan por disponer de una etapa previa de indagación o averiguación preliminar, orientada sobre todo a determinar: (i) si la conducta ocurrió; (ii) si es constitutiva de falta disciplinaria; (iii) el profesional que presuntamente intervino en ella ${ }^{63}$; (iv) si ha actuado bajo el amparo de una causal de exclusión de la responsabilidad ${ }^{64}$; (v) si el proceso no puede iniciarse porque se presentó alguna de las causales de extinción de la acción o la sanción disciplinaria ético-profesional, tales como la muerte del profesional, la prescripción o la rehabilitación ${ }^{65}$, o por haber operado el fenómeno de la cosa juzgada disciplinaria66.

No obstante, en desarrollo de los principios de eficacia, economía y celeridad, cuando la queja o informe permite establecer que es temerario, o se refiere a hechos disciplinariamente irrelevantes o de imposible ocurrencia, o si el investigado no ostenta la calidad de matriculado, o el anónimo no suministra datos o medios de prueba que permitan encausar la investigación, o los hechos presentados no hacen parte de las competencias del respectivo Consejo o Tribunal de Ética, lo procedente es inhibirse

61 Cf. Ley 576 de 2000, artículo 115, parágrafo; Ley 650 de 2001, artículo 75; Ley 911 de 2004, artículos 45, parágrafo, y 48; Ley 1090 de 2006, artículos 63, parágrafo, y 66; Ley 1123 de 2007, artículos 66, parágrafo, 78, 80, 104 y 105; Ley 1193 de 2008, artículos 15, parágrafo, y 16; Ley 1240 de 2008, artículo 25, parágrafo; Ley 1264 de 2008, artículos 71 y 80, parágrafo; Ley 1768 de 2015, artículos 24, parágrafo, 35 y 41.

62 Cf. Ley 576 de 2000, artículo 111; Ley 650 de 2001, artículo 75, parágrafo; Ley 911 de 2004, artículo 48; Ley 1090 de 2006, artículo 66; Ley 1123 de 2007, artículos 65, 104, 106; Ley 1193 de 2008, artículo 16; Ley 1264 de 2008, artículo 76.

63 Cf. Ley 576 de 2000, artículo 109; Ley 842 de 2003, artículo 64; Ley 1090 de 2006, artículo 64; Ley 1193 de 2008, artículo 14; Ley 1240 de 2008, artículo 26; Ley 1264 de 2008, artículo 74; Ley 1409 de 2010, artículo 42.

64 Cf. Ley 1123 de 2007, artículo 103; Ley 1768 de 2015, artículos 32 y 68.

65 Cf. Ley 1123 de 2007, artículos 23 y 26; Ley 1768 de 2015, artículos 16 y 19.

66 Cf. Ley 576 de 2000, artículo 111; Ley 650 de 2001, artículo 75; Ley 911 de 2004, artículo 48; Ley 1090 de 2006, artículo 66; Ley 1193 de 2008, artículo 16; Ley 1264 de 2008, artículo 76. 
de plano para iniciar la actuación disciplinaria, ordenando el archivo de las diligencias $y$, de ser el caso, su traslado a la autoridad competente ${ }^{67}$.

Para absolver todas estas dudas, varios regímenes disciplinarios facultan al operador para hacer uso de los medios de prueba legalmente reconocidos, así como oír en versión libre y espontánea al profesional que considere necesario ${ }^{68}$, aclarando que cuando no es posible identificar o individualizar al profesional autor de la presunta falta, es posible que la indagación o averiguación preliminar continúe hacia personas indeterminadas, hasta que se cumpla el término previsto en cada régimen disciplinario para agotarla sin que esta pueda extenderse a hechos distintos de los que son objeto de queja, informe o iniciación oficiosa y los que les sean conexos ${ }^{69}$.

En conclusión, cuando culmina el término procedimental de la indagación o averiguación preliminar y se satisfacen los fines para los cuales fue diseñada por el legislador, es procedente determinar si existe mérito para la apertura de una investigación formal; o en caso contrario, abstenerse de hacerlo y dictar resolución inhibitoria, de preclusión de la investigación, o auto de archivo del expediente ${ }^{70}$, específicamente cuando se demuestre que la conducta no existió, o que no es constitutiva de falta deontológica, o que el profesional investigado no la ha cometido, o que el proceso no puede iniciarse por haber muerto el profesional investigado o por prescripción de la acción o cosa juzgada ${ }^{71}$, decisiones que en todo caso deben someterse al principio de motivación.

\section{Investigación formal o instructiva, formulación de cargos y descargos}

Esta etapa inicia con la apertura de la investigación formal, en la que se señala la identidad del posible autor o autores, se comprueban sus credenciales profesionales, se cita para su declaración libre y espontánea, y se ordena la práctica de todas las pruebas necesarias para el esclarecimiento de los hechos y la demostración de la responsabilidad o la inocencia deontológica del profesional ${ }^{72}$. Esta providencia se

67 Cf. Ley 1123 de 2007, artículo 69; Ley 1768 de 2015, artículo 68, parágrafo.

68 Cf. Ley 842 de 2003, artículo 64, parágrafo; Ley 1409 de 2010, artículo 42.

69 Cf. Ley 1768 de 2015, artículo 68.

70 Cf. Ley 23 de 1981, artículo 80, literal a); Ley 35 de 1990, artículo 76, literal a).

71 Cf. Ley 911 de 2004, artículo 48; Ley 576 de 2000, artículo 115; Ley 1193 de 2008, artículo 16; Ley 1090 de 2006, artículo 66; Ley 1240 de 2008, artículo 28; Ley 1264 de 2008 , artículo 80.

72 Cf. Ley 911 de 2004, artículo 49; Ley 1090 de 2006, artículo 67; Ley 1193 de 2008, artículo 17; Ley 1240 de 2008, artículo 29. 
debe notificar al investigado dejando constancia en el expediente respectivo, informándole que tiene derecho a nombrar defensor, y que en caso de no designarlo se le asignará uno de oficio, con quien se surtirá la notificación y continuará representándolo en el trámite de la actuación ${ }^{73}$.

El término de duración de esta etapa puede variar de acuerdo con el número de investigados y el procedimiento disciplinario ético-profesional. Una vez notificada su apertura y practicadas las pruebas que allí se ordenaron, se debe proceder a dictar resolución o pliego de cargos cuando se encuentre establecida la falta deontológica o cuando existan indicios graves o pruebas que ameriten serios motivos de credibilidad sobre los hechos que son materia de investigación y responsabilidad deontológica disciplinaria del profesional ${ }^{74}$. En caso contrario, cuando se carece de alguno de estos presupuestos, lo pertinente es proferir resolución de preclusión o auto de archivo de las diligencias.

En cuanto al contenido de la decisión de formulación de cargos, el artículo 76 de la Ley 1768 de 2015 establece con precisión que deberá contener: (i) la descripción y determinación de la conducta investigada, con indicación de las circunstancias de tiempo, modo y lugar en que se realizó; (ii) las normas presuntamente violadas; (iii) la identificación del autor o autores de la falta; (iv) el análisis de las pruebas que fundamentan cada uno de los cargos formulados; (v) la exposición fundada de los criterios tenidos en cuenta para determinar la gravedad o levedad de la falta; (vi) la forma de culpabilidad; y (vii) el análisis de los argumentos expuestos por los sujetos procesales.

Empero, si el régimen disciplinario respectivo no determina cuáles son los elementos que debe contener la formulación de cargos, se considera que, con sujeción al principio de motivación, es menester dar aplicación a lo dispuesto en el artículo 47 de la Ley 1437 de 2011, el cual indica que en ese acto administrativo se deben señalar, con precisión y claridad, los hechos que lo originan, las personas naturales o jurídicas objeto de la investigación, las disposiciones presuntamente vulneradas y las sanciones o medidas que serían procedentes, contra lo cual no procede recurso alguno y debe ser notificado personalmente a los investigados.

A diferencia de lo anterior, en otros regímenes disciplinarios de los códigos de ética profesional se dispone que junto a la resolución o auto de apertura de la investigación formal se deben formular los respectivos cargos ${ }^{75}$. Pero, en su gran mayoría, estos regímenes coinciden en que una vez formulados los cargos y notificados al

73 Cf. Ley 1768 de 2015, artículo 72.

74 Cf. Ley 911 de 2004, artículo 52; Ley 1090 de 2006, artículo 70; Ley 1193 de 2008, artículo 20; Ley 1240 de 2008, artículo 32.

75 Cf. Ley 1409 de 2010, artículo 43; Ley 842 de 2003, artículo 63, modificado por el artículo 16 de la Ley 1796 de 2016. 
investigado, la providencia se debe notificar personalmente, y contra esta usualmente no se admite recurso ${ }^{76}$, se debe proceder a designar defensor de oficio si no lo hay, y correr traslado al investigado por el término que allí se determine para que presente por escrito sus descargos o a través de diligencia, dejando el expediente del proceso a su disposición durante el término que especifique la ley ${ }^{77}$.

Como manifestación del derecho de defensa y el principio de contradicción, en los descargos se faculta al investigado para aportar o solicitar pruebas adicionales directamente o a través de su apoderado, las cuales deben decretarse siempre y cuando sean conducentes, pertinentes y necesarias, y practicarse dentro del término señalado en la ley, enfatizando que varios regímenes aclaran que la renuencia del investigado o de su defensor a presentar descargos no interrumpe de ningún modo el trámite de la actuación $n^{78}$.

De esta manera, el deber de motivación y la precisión en la formulación de los cargos y las normas que presuntamente se vulneran es trascendental, a tal punto que varios regímenes disciplinarios conciben la vaguedad o ambigüedad de los cargos, o la omisión o imprecisión de las normas deontológicas en que se fundamente, como una causal autónoma de nulidad del procedimiento disciplinario ético-profesional ${ }^{79}$.

\section{Contenido del fallo y recursos}

Una vez rendidos los descargos y practicadas las pruebas conducentes, pertinentes y necesarias solicitadas por el investigado, previamente decretadas por el operador disciplinario, algunos regímenes disciplinarios ético-profesionales le conceden al investigado un término perentorio para presentar sus alegatos de conclusión ${ }^{80}$. Esto mientras que en los demás generalmente se omite esta actuación y se procede a

76 Cf. Ley 43 de 1990, artículo 28, parágrafo; Ley 576 de 2000, artículos 118, 119 y 120; Ley 650 de 2001, artículo 77; Ley 842 de 2003, artículo 66; Ley 911 de 2004, artículos 67 y 68; Ley 1090 de 2006, artículos 85 y 86; Ley 1123 de 2007, artículo 105; Ley 1193 de 2008, artículo 36; Ley 1264 de 2008, artículos 83 y 84. Ley 1409 de 2010, artículo 44; Ley 1768 de 2015, artículo 78.

77 Cf. Ley 23 de 1981, artículo 80, literal b); Ley 35 de 1989, artículo 76, literal b); Ley 43 de 1990, artículo 28, literal c); Ley 576 de 2000, artículos 117 a 121; Ley 650 de 2001, artículos 77 y 78; Ley 842 de 2003, artículo 67; Ley 911 de 2004, artículos 53 a 55; Ley 1090 de 2006, artículos 71 a 73; Ley 1193 de 2008, artículos 21 a 23; Ley 1240 de 2008, artículos 33 a 35; Ley 1264 de 2008, artículos 82 y 86; Ley 1409 de 2010, artículo 45; Ley 1768 de 2015 , artículo 79.

78 Cf. Ley 1768 de 2015, artículo 80.

79 Cf. Ley 911 de 2004, artículo 69, numeral 2; Ley 1090 de 2006, artículo 87, numeral 2; Ley 1193 de 2008, artículo 37; Ley 1240 de 2008, artículo 46, literal b).

80 Cf. Ley 842 de 2003, artículo 63, modificado por el artículo 16 de la Ley 1796 de 2016; Ley 1768 de 2015, artículo 82. 
expedir el fallo de primera instancia, cuyo sentido solo puede ser absolutorio o condenatorio ${ }^{81}$, quedando proscrita implícitamente la expedición de fallos inhibitorios que no decidan de fondo la situación jurídica del investigado.

En esta etapa definitiva, adquiere suma relevancia el principio de necesidad de la prueba, en la medida en que el fallo sancionatorio debe estar fundamentado en la prueba que conduzca a la certeza sobre la existencia de la falta disciplinaria y la responsabilidad del investigado ${ }^{82}$. A contrario sensu, en caso de no existir una prueba de estas características, es menester proceder a la absolución del investigado, en desarrollo de la presunción de inocencia consagrada en el artículo 29 de la Constitución.

En cuanto a los elementos constitutivos del fallo, sobresale el artículo 84 de la Ley 1768 de 2015, que es enfático al señalar que el fallo debe ser motivado y debe contener: (i) la identidad del investigado; (ii) un resumen de los hechos; (iii) el análisis de las pruebas en que se basa; (iv) el análisis y la valoración jurídica de los cargos, de los descargos y de las alegaciones que hubieren sido presentadas; (v) la fundamentación de la calificación de la falta; (vi) el análisis de culpabilidad; (vii) las razones de la sanción o de la absolución; y (viii) la exposición fundamentada de los criterios tenidos en cuenta para la graduación de la sanción y la decisión en la parte resolutiva.

Por su parte, el artículo 106 de la Ley 1123 de 2007 refiere que una vez realizada la audiencia de juzgamiento, el magistrado ponente dispone de cinco días para registrar su proyecto de fallo y la Sala dispone de cinco días para proferir sentencia, que deberá contener: (i) la identidad del investigado; (ii) un resumen de los hechos; (iii) el análisis de las pruebas que dan la certeza sobre la existencia de la falta y la responsabilidad del implicado, la valoración jurídica de los cargos, de los argumentos defensivos y de las alegaciones que hubieren sido presentadas; (iv) la fundamentación de la calificación de la falta y culpabilidad y de las razones de la sanción o de la absolución; y (v) la exposición debidamente razonada de los criterios tenidos en cuenta para la graduación de la sanción.

En concordancia con tales premisas, la Ley 1437 de 2011 en su artículo 49 indica que en el marco general del procedimiento administrativo sancionatorio, el funcionario competente debe proferir el acto administrativo definitivo dentro de los treinta días siguientes a la presentación de los alegatos de conclusión. Dicho acto debe contener los siguientes elementos básicos: (i) la individualización de la persona

81 Cf. Ley 911 de 2004, artículo 56; Ley 576 de 2000, artículo 122; Ley 650 de 2001, artículo 80; Ley 1090 de 2006, artículo 74; Ley 1193 de 2008, artículo 24; Ley 1240 de 2008, artículo 36; Ley 1264 de 2008, artículo 87.

82 Cf. Ley 650 de 2001, artículo 80; Ley 911 de 2004, artículo 57; Ley 1090 de 2006, artículo 75; Ley 1123 de 2007, artículos 97 y 106; Ley 1193 de 2008, artículo 25; Ley 1240 de 2008, artículo 37; Ley 1768 de 2015, artículo 63. 
natural o jurídica a sancionar; (ii) el análisis de hechos y pruebas con base en los cuales se impone la sanción; (iii) las normas infringidas con los hechos probados; y (iv) la decisión final de archivo o sanción y la correspondiente fundamentación.

Es decir que con sujeción al artículo 47 de la Ley 1437 de 2011, los regímenes disciplinarios de los códigos de ética profesional que no establezcan cuáles son los aspectos mínimos que deben contener sus fallos están en la obligación de incluir los elementos referenciados en el artículo 49 de la Ley 1437 de 2011 en sus fallos de instancia, pues reivindican varios principios esenciales del derecho disciplinario ético-profesional, tales como los probatorios, el derecho de defensa, la motivación, proporcionalidad y razonabilidad, entre otros.

Entre tanto, una vez proferido el fallo de primera instancia, es imperativa su notificación personal al investigado y eventualmente su comunicación al quejoso ${ }^{83}$, en lo cual son aplicables las formas de notificación subsidiarias que cada ordenamiento jurídico establezca, o en su defecto, las establecidas en los artículos 65 y siguientes de la Ley 1437 de 2011. Se precisa que tanto los recursos procedentes contra el fallo, como el término para interponerlos, también pueden variar según el régimen disciplinario y la clase de sanción que se impone ${ }^{84}$. En todo caso, en el derecho disciplinario ético-profesional es preponderante la consagración de los recursos de reposición, apelación y de hecho ${ }^{85}$, al igual que el mecanismo de consulta cuanto no se interponen los primeros ${ }^{86}$.

En esa medida, cuando se recibe el proceso en la segunda instancia, cada régimen disciplinario le define unos términos perentorios al Consejo o Tribunal Nacional para que profiera su fallo definitivo, y en algunos eventos le faculta para decretar pruebas de oficio y practicarlas en el término que allí se establezca, con el fin de aclarar las dudas que le puedan surgir al momento de desatar el recurso o mecanismo ${ }^{87}$. En

83 Cf. Ley 43 de 1990, artículo 28, parágrafo; Ley 650 de 2001, artículo 82; Ley 842 de 2003, artículo 70; Ley 911 de 2004, artículo 67; Ley 1090 de 2006, artículo 85; Ley 1123 de 2007, artículo 71; Ley 1193 de 2008, artículo 35; Ley 1240 de 2008, artículos 36 y 44; Ley 1264 de 2008, artículo 73 y 85; Ley 1409 de 2010, artículo 48; Ley 1768 de 2015, artículos 33 y siguientes.

84 Cf. Ley 23 de 1981, artículo 87 y siguientes; Ley 35 de 1990, artículo 83 y siguientes.

85 Cf. Ley 43 de 1990, artículo 28 literal d); Ley 576 de 2000, artículo 119; Ley 911 de 2004, artículo 68; Ley 650 de 2001, artículo 81; Ley 1090 de 2006, artículo 86; Ley 1240 de 2008, artículo 45; Ley 1264 de 2008, artículos 84 y 92.

86 Cf. Ley 842 de 2003, artículo 73; Ley 911 de 2004, artículo 58; Ley 1090 de 2006, artículo 76; Ley 1123 de 2007, artículo 59; Ley 1193 de 2008, artículo 26; Ley 1240 de 2008, artículo 38; Ley 1409 de 2010, artículo 50.

87 Cf. Ley 576 de 2000, artículos 126 a 128; Ley 911 de 2004, artículos 59 y 60; Ley 1090 de 2006, artículos 77 y 78; Ley 1123 de 2007, artículo 107; Ley 1193 de 2008, artículos 27 y 28; Ley 1240 de 2008, artículos 39 y 40; Ley 1264 de 2008, artículos 92 a 94; Ley 1768 de 2015, artículo 85 . 
este último aspecto, la Ley 1768 de 2015 en su artículo 85 señala que el recurso de apelación únicamente le otorga competencia al ad quem para revisar los aspectos impugnados y aquellos otros que resulten inescindiblemente vinculados al objeto de impugnación.

\section{Clases de sanciones, clasificación de las faltas y criterios para determinar su gravedad}

En el derecho disciplinario ético-profesional, las sanciones que generalmente se imponen cuando el profesional incurre en falta disciplinaria son: (i) la amonestación escrita o verbal; (ii) la censura; y (iii) la suspensión temporal del ejercicio de la profesión ${ }^{88}$. Adicional a las anteriores, algunos regímenes disciplinarios son más estrictos, ya que contemplan como falta disciplinaria la cancelación de la matrícula profesional o la exclusión del ejercicio profesional ${ }^{89}$, mientras que otros consagran sanciones de carácter pecuniario como la multa ${ }^{90}$.

Generalmente, estas faltas se clasifican en leves, graves y gravísimas, y con sujeción a los principios de razonabilidad y proporcionalidad ${ }^{91}$, algunos regímenes disciplinarios suelen definir los criterios generales de graduación que rigen al momento de determinar la gravedad o levedad de la falta ${ }^{92}$. Lo anterior sin perjuicio de los regímenes disciplinarios que definen taxativamente su catálogo de faltas gravísimas que dan lugar a la imposición de la sanción más drástica, como es la cancelación de la matrícula profesional, siendo esta una forma de sometimiento al principio de reserva de ley que busca restringir la discrecionalidad de la administración, contexto en el cual usualmente han concebido específicamente cuáles son sus faltas gravísimas ${ }^{93}$.

88 Cf. Ley 23 de 1981, artículo 83; Ley 35 de 1990, artículo 79; Ley 576 de 2000, artículo 133; Ley 911 de 2004, artículo 61; Ley 1090 de 2006, artículo 79; Ley 1240 de 2008, artículo 41.

89 Cf. Ley 650 de 2001, artículo 53; Ley 842 de 2003, artículo 47; Ley 1123 de 2007, artículo 44; Ley 1193 de 2008, artículo 29; Ley 1264 de 2008, artículo 95; Ley 1409 de 2010, artículo 27; Ley 1768 de 2015, artículo 8.

90 Cf. Ley 43 de 1990, artículo 23; Ley 1123 de 2007, artículo 40.

91 Cf. Ley 1123 de 2007, artículo 13.

92 Cf. Ley 842 de 2003, artículo 52; Ley 1123 de 2007, artículo 45; Ley 1409 de 2010, artículo 32; Ley 1768 de 2015, artículo 10.

93 Cf. Ley 842 de 2003, artículo 53; Ley 1409 de 2010, artículo 33; Ley 1768 de 2015, artículo 11. 
Así mismo, varios regímenes disciplinarios disponen específicamente cuáles son las circunstancias de atenuación ${ }^{94} \mathrm{o}$ agravación ${ }^{95}$ de la responsabilidad del profesional que se deben tener en cuenta al momento de la aplicación de la sanción disciplinaria ético-profesional. Aún más, otros regímenes disciplinarios contemplan escalas de sanciones, a manera de esquemas de dosificación de la sanción, que operan en función de la clasificación de la falta y la existencia de antecedentes disciplinarios del profesional, y que dan lugar a la clase de falta que se debe imponer y el término por el cual regirá. ${ }^{96}$

Empero, hay que referir que por la observancia del principio de legalidad dichas causales son taxativas y excluyentes, es decir que solamente tienen plena aplicación en el régimen disciplinario ético-profesional que las consagra de manera precisa e inequívoca, y que no es posible acudir a la analogía para adaptar causales de exclusión de responsabilidad de otros ordenamientos jurídicos en procura de su aplicación. Sin embargo, en caso de que el régimen disciplinario del código de ética profesional no disponga de criterios objetivos para la graduación de las sanciones, se considera que es imperativo aplicar los contenidos en el artículo 50 de la Ley 1437 de 2011.

Además, para dar plena observancia al principio de motivación y a lo dispuesto en el artículo 49 de la Ley 1437 de 2011, cabe indicar que todo fallo disciplinario debe contener la fundamentación completa y explícita sobre los motivos de la determinación cualitativa y cuantitativa de la sanción ${ }^{97}$.

\section{Ejecución, registro de la sanción y rehabilitación}

Una vez impuesta la sanción al profesional disciplinado y ejecutoriado el fallo disciplinario, es procedente que el Consejo o Tribunal haga efectiva la sanción, particularmente dando aviso a la Procuraduría General de la Nación, a las entidades que tengan que ver con el ejercicio profesional correspondiente, al registro de proponentes y contratistas, y a las agremiaciones de profesionales. Esto es para que hagan las anotaciones en sus registros y tomen las medidas pertinentes que permitan hacer efectiva la sanción, la cual también debe anotarse en los registros que lleve el Consejo

94 Cf. Ley 911 de 2004, artículo 43; Ley 1090 de 2006, artículo 61; Ley 1123 de 2007, artículo 45; Ley 1193 de 2008, artículo 11; Ley 1240 de 2008, artículo 23; Ley 1264 de 2008, artículo 98.

95 Cf. Ley 911 de 2004, artículo 44; Ley 1090 de 2006, artículo 62; Ley 1123 de 2007, artículo 54; Ley 1193 de 2008, artículo 12; Ley 1240 de 2008, artículo 24; Ley 1264 de 2008, artículo 99.

96 Cf. Ley 842 de 2003, artículos 48 y 54; Ley 1409 de 2010, artículos 28 y 34; Ley 1768 de 2015, artículos 9 y 12.

97 Cf. Ley 1123 de 2007, artículo 46. 
o Tribunal respectivo, con el fin de que conste en el certificado de vigencia y antecedentes disciplinarios durante el término de duración de la sanción ${ }^{98}$, mecanismo que la Corte Constitucional encontró ajustado a la Carta Política desde la Sentencia C-060 de 1994.

En cuanto al momento de inicio del cómputo de la sanción, es de anotar que algunos regímenes disciplinarios establecen que aquel inicia a partir de la fecha de ejecutoria de la providencia o acto administrativo que la ordenó ${ }^{99}$, en tanto que en otros regímenes se define que la sanción empezará a computarse a partir de la fecha de la comunicación personal o de la entrega por correo certificado que se haga al profesional sancionado de la decisión del Consejo o Tribunal correspondiente sobre la apelación o la consulta. ${ }^{100}$

Para el caso de la ingeniería y sus profesiones afines y auxiliares, el artículo 18 de la Ley 1796 de 2016 es enfático al mencionar cuáles son los efectos jurídicos que se desprenden de la ejecutoria de la sanción de suspensión o cancelación. El artículo señala que, como consecuencia de ello, el sancionado no puede ejercer su profesión en el sector público o privado durante el término de la sanción, lo cual implica además su desvinculación inmediata del empleo, cargo, representación o dignidad que ostente, o la terminación del contrato si accedió a él con motivo, ocasión o en razón de su profesión o de su título profesional.

Sin embargo, el artículo 28 de la Constitución Política prohíbe la imposición de penas o sanciones permanentes, perpetuas e imprescriptibles, proscripción que también se predica del derecho disciplinario ético-profesional tal como la Corte Constitucional lo reconoció en la Sentencia C-290 de 2008. En vista de lo anterior, varios de sus regímenes disciplinarios consagran la figura de la rehabilitación en el ejercicio profesional como una forma de extinción de la sanción disciplinaria que puede ser solicitada por el profesional sancionado con cancelación de la matrícula o tarjeta ${ }^{101}$ cuando ha transcurrido un determinado periodo contabilizado desde la ejecutoria de la sanción, no haya incumplido la sanción impuesta y además apruebe los cursos de capacitación que le indique el respectivo Consejo ${ }^{102}$, con el fin de ejercer nuevamente su profesión.

98 Cf. Ley 576 de 2000, artículo 135; Ley 650 de 2001, artículo 55; Ley 842 de 2003, artículo 75; Ley 1123 de 2007, artículo 47; Ley 1264 de 2008, artículo 100; Ley 1409 de 2010, artículo 51; Ley 1768 de 2015, artículos 86 y 88.

99 Cf. Ley 1768 de 2015, artículo 87.

100 Cf. Ley 842 de 2003, artículo 74; Ley 1409 de 2010, artículo 50.

101 Cf. Ley 1123 de 2007, artículo 26, numeral 3; Ley 1768 de 2015, artículo 19, numeral 3.

102 Cf. Ley 1123 de 2007, artículos 108 y 109; Ley 1768 de 2015, artículos 13 y 14; Ley 1796 de 2016, artículo 19. 
Cumplidos los requisitos legales para solicitar la rehabilitación, la petición se suele someter a un procedimiento breve conformado por las siguientes cinco etapas: (i) admisión de la solicitud y apertura a pruebas; (ii) rechazo de la solicitud cuando no se cumple con el requisito temporal, mediante auto motivado susceptible del recurso de reposición; (iii) decreto de pruebas conducentes solicitadas con la petición de rehabilitación y las que oficiosamente se estimen necesarias; (iv) periodo probatorio y fallo, para lo cual las pruebas deben ser practicadas en un término no superior a treinta días, y posteriormente la Sala cuenta con diez días para decidir, determinación que es susceptible del recurso de apelación; y (v) comunicación, que procede cuando se encuentre en firme el auto que ordena la rehabilitación, y se oficia a las mismas autoridades a quienes se comunicó la exclusión para los efectos legales pertinentes ${ }^{103}$.

En todo caso, si el régimen disciplinario ético-profesional contempla la figura de la rehabilitación, pero no define un procedimiento concreto para su trámite ante el Consejo respectivo, se considera que es procedente dar aplicación al procedimiento administrativo general previsto en los artículos 34 y siguientes de la Ley 1437 de 2011.

\section{Nulidades}

Las nulidades guardan una estrecha relación con el principio de eficacia previsto en el artículo 3 de la Ley 1437 de $2011^{104}$, en virtud del cual las autoridades administrativas deben buscar que los procedimientos logren su finalidad y se les faculta para remover de oficio los obstáculos formales, evitar decisiones inhibitorias, dilaciones o retardos, y sanear las irregularidades procedimentales que se presenten, en procura de la efectividad del derecho material objeto de la actuación administrativa. Este postulado encuentra su desarrollo en el artículo 41 de la Ley 1437 de 2011, que permite a las autoridades en cualquier momento antes de la expedición del acto, de oficio o a petición de parte, corregir las irregularidades que se hayan presentado en la actuación administrativa para ajustarla a derecho, y adoptar las medidas necesarias para concluirla.

Para el derecho disciplinario ético-profesional, esta facultad se expresa en la posibilidad que tiene el operador disciplinario de sanear las falencias advertidas durante el trámite del procedimiento disciplinario, de oficio o a petición de parte, antes de proferir el fallo de instancia. Esto se da a través de la declaratoria de una nulidad específica que deja sin efectos las actuaciones administrativas que se encuentran viciadas y las retrotrae para que se surtan de nuevo (prerrogativa que de ningún modo se puede interpretar como una patente de corso en contra del investigado) para subsanar

103 Cf. Ley 1123 de 2007, artículo 110; Ley 1768 de 2015, artículo 15.

104 Numeral 11. 
actuaciones que, por la inactividad o negligencia del Estado como titular de la acción disciplinaria ético-profesional, no se hayan evacuado en debida forma.

Las causales de nulidad que comúnmente se incluyen en algunos regímenes disciplinarios de los códigos de ética profesional son la falta de competencia, la ambigüedad de los cargos, la existencia de irregularidades sustanciales y la violación del derecho de defensa ${ }^{105}$.

Por su parte, las Leyes 1123 de 2007 y 1768 de 2015 permiten que en cualquier estado de la actuación disciplinaria, cuando el funcionario que conozca del asunto advierta la existencia de una de las causales previstas en dichas normas, declare la nulidad de lo actuado y ordene que se reponga la actuación que dependa del acto declarado nulo para que se subsane el defecto ${ }^{106}$. Se aclara que cuando es el interviniente quien alega la nulidad, debe especificar la causal que invoca, las razones en que se funda y no podrá formular una nueva, sino por causal diferente o por hechos posteriores $^{107}$, para lo cual en consonancia con la doctrina y la jurisprudencia, establecen una serie de principios que orientan la declaratoria de las nulidades y su convalidación. ${ }^{108}$

\section{Prescripción y caducidad}

De vieja data, la doctrina y la jurisprudencia nacional han delimitado los conceptos de caducidad y prescripción. Conciben la primera como un presupuesto procesal de la acción que hace referencia al ejercicio de un derecho dentro de los plazos fijados por el legislador, so pena de impedir el establecimiento de una relación jurídico-procesal válida; mientras que por prescripción se concluye que hace referencia a un modo para el surgimiento de derechos subjetivos, como es la prescripción adquisitiva o usucapión, o para extinguir obligaciones, como ocurre con la prescripción propiamente dicha ${ }^{109}$.

Sin embargo, esta diferenciación no parece reflejarse en los regímenes disciplinarios de los códigos de ética profesional, puesto que se suele aludir a la una o la otra para significar el lapso que tiene el Estado para el ejercicio de la acción disciplinaria ético-profesional, o para hacer efectiva la sanción que impuso como su resultado, en

105 Cf. Ley 650 de 2001, artículo 84; Ley 911 de 2004, artículo 69; Ley 1090 de 2006, artículo 87; Ley 1123 de 2007, artículos 98 a 101; Ley 1193 de 2008, artículo 37; Ley 1240 de 2008, artículo 46; Ley 1768 de 2015, artículos 64 a 67.

106 Ley 1123 de 2007, artículo 99; Ley 1768 de 2015, artículo 65.

107 Ley 1123 de 2007, artículo 100; Ley 1768 de 2015, artículo 66.

108 Ley 1123 de 2007, artículo 101; Ley 1768 de 2015, artículo 67.

109 Cf. Corte Constitucional de Colombia. Sentencia SU-242 de 2015. 
razón a que algunos de ellos generalmente indican que esta acción prescribe a los cuatro o cinco años. Dicho periodo varía de acuerdo con el ordenamiento jurídico, contados desde el día en que se cometió la última acción u omisión constitutiva de falta contra la deontología profesional, marco en el cual la formulación del pliego de cargos interrumpe la prescripción y exige contabilizar nuevamente el término desde el día de la interrupción pero reducido a dos años, a lo que agregan que la sanción prescribe a los tres o cinco años, lapso que también cambia en algunos regímenes, contados desde la fecha de la ejecutoria de la providencia que la imponga ${ }^{110}$.

Entre tanto, otros regímenes disciplinarios se refieren, bajo esos mismos supuestos, a la caducidad de la acción y a la prescripción de la sanción ${ }^{111}$, y en cuanto al momento de inicio de la prescripción de la acción disciplinaria ético-profesional, sobresalen las Leyes 1123 de 2007 y 1768 de 2015 que son más específicas al indicar que la acción prescribe en cinco años, "contados para las faltas instantáneas desde el día de su consumación y para las de carácter permanente o continuado desde la realización del último acto ejecutivo de la misma"112; y cuando se trata de varias conductas juzgadas en un solo proceso, precisan que la prescripción de las acciones se cumple independientemente para cada una de ellas.

Así mismo, las leyes referidas permiten al disciplinable renunciar a la prescripción de la acción dentro del término de ejecutoria del auto que la decrete, caso en el cual la acción solamente puede adelantarse por un término máximo de dos años, contados a partir de la presentación personal de la solicitud, y si vencido ese lapso no se hubiese proferido y ejecutoriado decisión definitiva, es procedente la declaratoria de prescripción ${ }^{113}$, concluyendo que la sanción disciplinaria prescribe en el término de cinco años, contados a partir de la ejecutoria del fallo $0^{114}$.

De otro lado, la Ley 1796 de 2016 distingue, para el caso de la ingeniería y sus profesiones afines o auxiliares, que la acción disciplinaria ético-profesional caduca a los cinco años contados "a partir de la fecha en la que se cometió el último acto constitutivo de la falta o en la que se tuvo conocimiento de la misma" 115, y además precisa que el auto que ordena la apertura de la investigación preliminar interrumpe el término

110 Cf. Ley 576 de 2000, artículo 129; Ley 650 de 2001, artículo 85; Ley 911 de 2004, artículo 70; Ley 1090 de 2006, artículo 88; Ley 1193 de 2008, artículo 38; Ley 1240 de 2008, artículo 47.

111 Cf. Ley 1264 de 2008, artículo 64; Ley 1409 de 2010, artículo 52.

112 Ley 1123 de 2007, artículo 24; Ley 1768 de 2015, artículo 17.

113 Ley 1123 de 2007, artículo 25; Ley 1768 de 2015, artículo 18.

114 Ley 1123 de 2007, artículo 27; Ley 1768 de 2015, artículo 20.

115 Artículo 15, modificatorio del artículo 60 de la Ley 842 de 2003. 
de caducidad, y que el proceso disciplinario prescribe en cinco años contabilizados desde la expedición de dicho auto'116.

Finalmente, se considera que los regímenes disciplinarios de los códigos de ética profesional que no dispongan de términos de prescripción o caducidad de la acción o la sanción disciplinaria ético-profesional deben aplicar imperativamente lo establecido en el artículo 52 de la Ley 1437 de 2011. Este artículo establece como regla general que la facultad que tienen las autoridades para imponer sanciones caduca a los tres años de ocurrido el hecho, la conducta u omisión que pudiere ocasionarlas, exigiendo además que dentro de dicho término el acto administrativo que impone la sanción haya sido expedido y notificado, y que cuando se trate de un hecho o conducta continuada, este término se contabiliza a partir del día siguiente a aquel en que cesó la infracción y/o ejecución, en tanto que la sanción decretada por acto administrativo prescribe a los cinco años contados a partir de la fecha de la ejecutoria.

\section{CONCLUSIONES}

Las instituciones jurídico-procesales analizadas dan cuenta de la enorme influencia que el derecho disciplinario ético-profesional recibe del derecho disciplinario y del derecho penal. Por tal razón, los avances dogmáticos que se presenten en estas dos últimas ramas del derecho siempre serán objeto de discusión y aplicación permanente en el seno de la primera, subrayando que, en paralelo, el estudio presentado también destaca las especificidades procedimentales y los rasgos particulares del derecho disciplinario ético-profesional, que refuerzan la premisa que lo reivindica como rama autónoma del derecho.

Empero, los regímenes disciplinarios de los códigos de ética profesional objeto del presente estudio muestran una disparidad en la inclusión de sus instituciones jurídico-procesales, toda vez que algunos sobresalen por su garantismo procesal. Tal es el caso de los definidos en las Leyes 650 de 2001, 911 de 2004, 1090 de 2006, 1123 de 2007, 1193 de 2008, 1240 de 2008 y 1768 de 2015, que determinan con meridiana precisión: sus principios rectores, las causales de extinción de la acción y la sanción disciplinaria ético-profesional, las causales y los principios rectores para la declaratoria de nulidades procedimentales, los criterios objetivos para la dosificación de las sanciones, reglas claras para la prescripción y la caducidad, y la posibilidad de rehabilitación del ejercicio profesional, entre otros aspectos que contribuyen a disminuir su 
discrecionalidad sancionatoria, en concordancia con los estándares constitucionales y convencionales que se han elaborado sobre el particular.

En ese sentido, también se pudo evidenciar que otros regímenes disciplinarios de los códigos de ética profesional son más restringidos, específicamente aquellos que fueron expedidos con antelación a la Constitución de 1991, tales como los contenidos en las Leyes 23 de 1981, 35 de 1989 y 43 de 1990. Si bien estos regímenes disponen de sistemas de remisión normativa que suplen en cierta medida sus vacíos sustanciales y procedimentales, es menester que dispongan de sus propias instituciones jurídico-procesales que desarrollen los núcleos esenciales del debido proceso, por lo que urge su actualización para ponerlos a tono con los estándares constitucionales y convencionales ya referidos, labor en la que los regímenes disciplinarios ético-profesionales de segunda generación les podrían ser de suma utilidad.

En resumidas cuentas, partiendo de la dignidad humana como pilar esencial del Estado Social de Derecho en Colombia, que le exige tener como eje principal de su objeto al ser humano, el ejercicio del derecho disciplinario ético-profesional y la imposición de las sanciones que de él se derivan deben aplicarse de forma proporcional y razonable, bajo el sometimiento de los principios constitucionales y legales que le son predicables.

\section{REFERENCIAS}

Acto Legislativo 01 de 1918. Por el cual se sustituye el artículo 44 de la Constitución. Agosto 27 de 1918. DO N. ${ }^{\circ} 16.476$.

Acto Legislativo 01 de 1921. Por el cual se sustituye el Acto Legislativo número 1 de 1918. Octubre 18 de 1921. DO N. ${ }^{\circ} 17.934$.

Acto Legislativo 02 de 1931. Sustitutivo del Acto número 1 de 1921. Noviembre 19 de 1931. Do N. ${ }^{\circ}$ 21.849 .

Acto Legislativo 01 de 1932. Sustitutivo del Acto número 1 de 1921. Septiembre 8 de 1932. Do N. 22.087.

Acto Legislativo 01 de 1936. Reformatorio de la Constitución. Agosto 5 de 1936. Do N. 2 23.263.

Acto Legislativo 02 de 2015. Por medio del cual se adopta una reforma de equilibrio de poderes y reajuste institucional y se dictan otras disposiciones. Julio 1 de 2015. Do N. ${ }^{\circ} 49.560$. 
Carlos Mario Isaza. TeORÍA GENeRAL DEL DERECHO DISCIPLINARIO. ASPECTOS HISTÓRICOS, SUSTANCIALES Y PROCESALES. 2. ed. Bogotá: Editorial Temis. (2009).

Congreso de la República de Colombia. Ponencia: Derecho al Trabajo. Gaceta Constitucional N. 85. Ponentes: Juan Carlos Esguerra Portocarrero, Angelino Garzón, Guillermo Guerrero Figueroa, Germán Toro, Antonio Yepes Parra.

Constitución Provincial de Cundinamarca [Const.]. Abril 4 de 1811. (Colombia).

Constitución Política de la Nueva Granada [Const.]. Marzo 1 de 1832. (Colombia).

Constitución Política de Colombia [Const.]. Agosto 5 de 1886. (Colombia).

Constitución Política de Colombia [Const.]. Julio 4 de 1991. (Colombia).

Consejo de Estado de Colombia, Sala de Consulta y Servicio Civil. Radicación número: 1100103-06-000-2017-00079-00(2340). (C.P. Germán Alberto Bula Escobar; diciembre 12 de 2017).

Consejo de Estado de Colombia, Sección Primera de la Sala de lo Contencioso Administrativo. Radicación número: 25000-23-24-000-2011-00409-01. (c.P. Oswaldo Giraldo López; julio 26 de 2018).

Organización de Estados Americanos (OEA). Convención Americana sobre Derechos Humanos "Pacto de San José". Noviembre 22 de 1969. San José: OEA.

Corte Constitucional de Colombia. Sentencia C-606 de 1992. (M.P. Ciro Angarita Barón; diciembre 14 de 1992).

Corte Constitucional de Colombia. SentenciA C-104 de 1993. (M.P. Alejandro Martínez Caballero; marzo 11 de 1993).

Corte Constitucional de Colombia. SenTEnCIA C-131 de 1993. (M.P. Alejandro Martínez Caballero; abril 1 de 1993).

Corte Constitucional de Colombia. SEnTEnCIA C- 060 de 1994. (M.P. Carlos Gaviria Diaz; febrero 17 de 1994).

Corte Constitucional de Colombia. SEnTEnCIA C-214 de 1994. (M.P. Antonio Barrera Carbonell; abril 28 de 1994). 
Corte Constitucional de Colombia. SEnTENCIA C-037 de 1996. (M.P. Vladimiro Naranjo Mesa; febrero 5 de 1996)

Corte Constitucional de Colombia. Sentencia C-190 de 1996. (M.P. Hernando Herrera Vergara; mayo 8 de 1996).

Corte Constitucional de Colombia. SEnTEnCIA C-597 de 1996. (M.P. Alejandro Martínez Caballero; noviembre 6 de 1996).

Corte Constitucional de Colombia. SentenciA C-399 de 1999. (M.P. Alejandro Martínez Caballero; junio 2 de 1999).

Corte Constitucional de Colombia. Sentencia C-012 de 2000. (M.P. Alfredo Beltrán Sierra; enero 19 de 2000).

Corte Constitucional de Colombia. SentenciA C-530 de 2000. (M.P. Antonio Barrera Carbonell; mayo 10 de 2000).

Corte Constitucional de Colombia. SEnTEnCIA C-836 de 2001. (M.P. Rodrigo Escobar Gil; agosto 9 de 2001).

Corte Constitucional de Colombia. SentencIA C-948 de 2002. (M.P. Álvaro Tafur Galvis; noviembre 6 de 2002).

Corte Constitucional de Colombia. SEnTENCIA C-406 de 2004. (M.P. Clara Inés Vargas Hernández; mayo 4 de 2004).

Corte Constitucional de Colombia. SEnTEnCIA C-340 de 2006. (M.P. Jaime Córdoba Triviño; mayo 3 de 2006).

Corte Constitucional de Colombia. SENTENCIA C-884 de 2007. (M.P. Jaime Córdoba Triviño; octubre 24 de 2007).

Corte Constitucional de Colombia. SENTENCIA C-290 de 2008. (M.P. Jaime Córdoba Triviño; abril 2 de 2008).

Corte Constitucional de Colombia. Sentencia C-762 de 2009. (M.P. Juan Carlos Henao Pérez; octubre 29 de 2009).

Corte Constitucional de Colombia. Sentencia C-539 de 2011. (M.P. Luis Ernesto Vargas Silva; julio 6 de 2011). 
Corte Constitucional de Colombia. SEnTENCIA C-899 de 2011. (M.P. Jorge Ignacio Pretelt Chaljub; noviembre 30 de 2011).

Corte Constitucional de Colombia. Sentencia T-704 de 2012. (M.P. Luis Ernesto Vargas Silva; septiembre 4 de 2012).

Corte Constitucional de Colombia. Sentencia C-385 de 2015. (M.P. Alberto Rojas Ríos; junio 24 de 2015).

Corte Constitucional de Colombia. SEnTEnCIA SU-242 de 2015. (M.P. Gloria Stella Ortiz Delgado; abril 30 de 2015).

Corte Constitucional de Colombia. SentenCIA C-274 de 2016. (M.P. Luis Ernesto Vargas Silva; mayo 25 de 2016).

Corte Constitucional de Colombia. SENTENCIA C-469 de 2016. (M.P. Luis Ernesto Vargas Silva; agosto 31 de 2016)

Corte Constitucional de Colombia. Sentencia C-053 de 2018. (M.P. Gloria Stella Ortiz Delgado; mayo 30 de 2018)

Corte Constitucional de Colombia. SENTENCIA C-246 de 2019. (M.P. Alejandro Linares Cantillo; junio 5 de 2019).

Corte Interamericana de Derechos Humanos. Control De convencionalidad. Cuadernillo de Jurisprudencia de la Corte Interamericana de Derechos Humanos N. ${ }^{\circ}$ 7. 2017. https://www. corteidh.or.cr/sitios/libros/todos/docs/cuadernillo7.pdf

Corte Suprema de Justicia. Sentencia 51 de 1983. (M.P. Manuel Gaona Cruz; abril 14 de 1983).

Decreto 592 de 1905. Por el cual se reglamenta el ejercicio de la profesión de Medicina. Junio 08 de 1905. Do N..'12.378.

Decreto 1165 de 1905. Por el cual se reglamenta el ejercicio de la profesión de abogado. Octubre 03 de 1905. Do N. ${ }^{\circ} 12.470$.

Decreto 1099 de 1930. Por el cual se reglamenta la Ley 35 de 1929, sobre ejercicio de las profesiones médicas y algunas otras. Julio 08 de 1930. Do N. ${ }^{\circ} 21.440$.

Decreto 1624 de 1930. Por el cual se reforma el Decreto número 1099 de 1930. Octubre 01 de 1930. DO N. ${ }^{\circ} 21.518$. 
Decreto 1672 de 1930. Por el cual se prorroga el término señalado por el Decreto número 1099 de 1930, para la reválida de las licencias médicas. Octubre 06 de 1930. Do N. ${ }^{\circ} 21.519$.

Decreto 62 de 1931. Por el cual se reforman los Decretos números 1099 y 1672 de 1930. Enero 15 de 1931. DO N. ${ }^{\circ} 21.600$.

Decreto 507 de 1931. Por el cual se reforma el artículo 9 del Decreto 1099 de 1930. Marzo 11 de 1931. DO N. ${ }^{\circ} 21.659$.

Decreto 393 de 1932. Por el cual se reforman y adicionan los Decretos números 1099 de 1930 y 507 de 1931. Marzo 04 de 1932. Do N. ${ }^{\circ} 21.933$.

Decreto 986 de 1932. Por el cual se adiciona y reforma el marcado con el número 1099 de 1930. Abril 26 de 1932. DO N. ${ }^{\circ} 22.010$.

Decreto 2736 de 1936. Por el cual se reglamenta la ley 67 de 1935, sobre ejercicio de la medicina (reinserción). Noviembre 03 de 1936. Do N. ${ }^{\circ} 23.337$.

Decreto 1135 de 1952. Por el cual se dictan algunas disposiciones sobre Escalafón Nacional de Enseñanza Primaria. Junio 21 de 1952. Do N.ํ․ 27.931.

Decreto 1782 de 1954. Por el cual se reglamenta el ejercicio de las profesiones de Ingeniería y Arquitectura. Junio 08 de 1954. Do N. 28.518.

Decreto 2831 de 1954. Código de ética de la medicina. Septiembre 23 de 1954. Do N. ${ }^{\circ} 28.594$.

Decreto 960 de 1970. Por el cual se expide el Estatuto de Notariado. Junio 20 de 1970. Do N. 33.118.

Decreto 2277 de 1979. Por el cual se adoptan normas sobre el ejercicio de la profesión docente. Septiembre 14 de 1979. Do N. ${ }^{\circ} 35.374$.

Decreto 2480 de 1986. Por el cual se reglamenta parcialmente el Decreto extraordinario 2277 de 1979. Julio 31 de 1986. Do N. ${ }^{\circ} 37.579$.

Decreto 2584 de 1993. Por el cual se modifica el Reglamento de Disciplina para la Policía Nacional. Diciembre 22 de 1993. Do N. ${ }^{\circ} 41.151$.

Decreto 953 de 1997. Por el cual se dicta el Reglamento de Disciplina para el Personal de los Cuerpos de Bomberos. Abril 3 de 1997. Do N. ${ }^{\circ} 43.013$. 
Decreto 1797 de 2000. Por el cual se expide el Reglamento de Régimen Disciplinario para las Fuerzas Militares. Septiembre 14 de 2000. Do N. ${ }^{\circ} 44.161$.

Decreto 1798 de 2000. Por el cual se modifican las normas de disciplina y ética para la Policía Nacional. Septiembre 14 de 2000. Do N. ${ }^{\circ} 44.161$.

Decreto 1278 de 2002. Por el cual se expide el Estatuto de Profesionalización Docente. Junio 19 de 2002. DO N.' 44.840.

Decreto 2723 de 2014. Por el cual se modifica la estructura de la Superintendencia de Notariado y Registro. Diciembre 29 de 2014. Do N. ${ }^{\circ} 49.379$

Decreto 697 de 2019. Por el cual se reglamenta el artículo 38 de la Ley 1862 de 2017 y se adiciona el Decreto 1070 del 2015 "Decreto Único Reglamentario del Sector Administrativo de Defensa". Abril 24 de 2019. DO N. ${ }^{\circ} 50.934$.

Hugo Marín. El principio de proporcionalidad en el derecho administrativo colombiano. SerIE DERECHO AdMINISTRATIVO 31. 2018.

Jaime Cubides Cárdenas, et al. El CONTROL DE CONVENCIONALIDAD: FUNDAMENTACIÓN E IMPLEMENTACIÓN DESDE EL SISTEMA INTERAMERICANO DE DERECHOS HUMANOS. Bogotá: Editorial Universidad Católica de Colombia. (2016).

Jaime Giraldo. Lo ÉTICO EN EL DERECHO. Bogotá: Librería Ediciones del Profesional Ltda. (2013).

José Adolfo González. DeRECHO DISCIPLINARIO Y BIEN JURíDICO. Bogotá: Instituto de Estudios del Ministerio Público. (2016).

Juan Laverde. MANUAL DE PROCEDIMIENTO ADMINISTRATIVO SANCIONATORIO. Bogotá: Legis Editores. (2016).

Ley 71 de 1890. Por la cual se crea la Academia de Medicina Nacional. Noviembre 22 de 1890. Do N. ${ }^{\circ} 8255$.

Ley 12 de 1905. Por el cual autoriza la reglamentación del ejercicio de la profesión de la medicina y la abogacía. Abril 08 de 1905. Do N. ${ }^{\circ} 12.327$.

Ley 40 de 1907. Sobre reformas judiciales. Junio 15 de 1907. Do N. 13.007.

Ley 37 de 1912. Por la cual se derogan varias disposiciones legales. Octubre 11 de 1912. Do N. ${ }^{\circ}$ 14.731 . 
Ley 83 de 1914. Por la cual se reglamenta el ejercicio de las profesiones médicas. Noviembre 19 de 1914. DO N. 15.350.

Ley 67 de 1920. Por la cual se reglamenta el ejercicio de la profesión médica. Noviembre 11 de 1920. DO N. ${ }^{\circ} 17.406$.

Ley 85 de 1922. Por la cual se reforma las leyes que reglamentan el ejercicio de la profesión médica y sus auxiliares. Noviembre 29 de 1922. Do N. ${ }^{\circ} 18.639$.

Ley 62 de 1928. Por la cual se reglamenta el ejercicio de la abogacía. Octubre 16 de 1928. Do N. 20923.

Ley 35 de 1929. Por la cual se reglamenta el ejercicio de la profesión de medicina en Colombia. Noviembre 22 de 1929. DO N. ${ }^{\circ} 21.253$.

Ley 21 de 1931. Por la cual se adiciona y se reforma la Ley 62 de 1928, sobre ejercicio de la abogacía y se dictan otras disposiciones. Febrero 07 de 1931. Do N. ${ }^{\circ} 21.617$.

Ley 67 de 1935. Por la cual se reglamenta el ejercicio de la profesión de medicina y cirugía. Diciembre 04 de 1935. Do N. ${ }^{\circ} 23.055$.

Ley 48 de 1936. Sobre vagos, maleantes y rateros. Marzo 13 de 1936. Do N. 23.147.

Ley 2 de 1937. Por la cual se fija el sueldo mínimo del maestro y se dictan disposiciones sobre escuelas primarias, y por la cual se aclara y adiciona la Ley 14 de 1935. Enero 29 de 1937. DO N. ${ }^{\circ} 23.425$

Ley 94 de 1937. Por la cual se reglamenta el ejercicio de la profesión de Ingeniería. Octubre 28 de 1937. DO N. ${ }^{\circ} 23.640$.

Ley 43 de 1945. Por la cual se crea el Escalafón Nacional de Enseñanza Secundaria. Diciembre 17 de 1945. DO N.'26.014.

Ley 69 de 1945. Por la cual se desarrolla el artículo 40 de la Constitución Nacional, sobre ejercicio de la abogacía. Diciembre 21 de 1945. Do N. ${ }^{\circ} 26.019$.

Ley 64 de 1947. Por la cual se aumentan las pensiones de jubilación de los maestros de escuela primaria oficial y se reforma el artículo 5 de la Ley 43 de 1945. Diciembre 23 de 1947. Do N. 26.619. 
Ley 20 de 1960. Por la cual se reforma los artículos 5 de la Ley 43 de 1945 y 7 de la Ley 64 de 1947. Septiembre 27 de 1960. Do N. ${ }^{\circ} 30.349$.

Ley 74 de 1968. Por la cual se aprueban los "Pactos Internacionales de Derechos Económicos, Sociales y Culturales, de Derechos Civiles y Políticos", así como el Protocolo Facultativo de este último, aprobados por la Asamblea General de las Naciones Unidas en votación unánime, en Nueva York, el 16 de diciembre de 1966. Diciembre 26 de 1968. Do N. 32.682.

Ley 14 de 1971. Por la cual se determinan condiciones de ingreso y ascenso en el Escalafón Nacional de Enseñanza Primaria y Secundaria, y se reviste de facultades extraordinarias al Presidente de la República para reajustar asignaciones y fijar estímulos al profesorado dependiente del Ministerio de Educación Nacional. Octubre 23 de 1971. DO N.³3.456.

Ley 16 de 1972. Por medio de la cual se aprueba la Convención Americana sobre Derechos Humanos "Pacto de San José de Costa Rica", firmado en San José, Costa Rica el 22 de noviembre de 1969. Diciembre 30 de 1972. Do N. 33.780.

Ley 9 de 1974. Por la cual se reglamenta el ejercicio de la profesión de Geólogo y se dictan otras disposiciones. Septiembre 30 de 1974. Do N. 34.185.

Ley 53 de 1975. Por la cual se reconoce la profesión de Químico y se reglamenta su ejercicio en el país. Diciembre 18 de 1975. Do N. ${ }^{3} 34.475$.

Ley 18 de 1976. Por la cual se reglamenta el ejercicio de la profesión de Ingeniero Químico en el país, reconocida por el Ministerio de Educación Nacional. Febrero 19 de 1976. Do N. 34.503.

Ley 53 de 1977. Por la cual se reglamenta el ejercicio de la profesión de trabajador social y se dictan otras disposiciones. Diciembre 23 de 1977. DO N. ${ }^{\circ} 34.940$.

Ley 8 de 1979. Por la cual se otorga unas facultades extraordinarias para establecer la naturaleza, características y competentes del Sistema de Educación Post-secundaria, se fijan requisitos para la creación y funcionamiento de instituciones públicas y privadas de educación post-secundaria, para reorganizar la Universidad Nacional de Colombia y las demás Universidades e Institutos Oficiales de nivel post-secundario y para expedir las normas sobre Escalafón Nacional para el Sector Docente y derogar unas normas. Enero 24 de 1979. Do N.3 35.191.

Ley 23 de 1981. Por la cual se dictan normas en materia de ética médica. Febrero 18 de 1981. Do N. ${ }^{\circ} 35.711$.

Ley 60 de 1981. Por la cual se reconoce la Profesión de Administración de Empresas y se dictan normas sobre su ejercicio en el país. Noviembre 04 de 1981. Do N. ${ }^{3} 35.889$. 
Ley 58 de 1983. Por la cual se reconoce la Psicología como una profesión y se reglamenta su ejercicio en el país. Diciembre 28 de 1983. Do N. ${ }^{\circ} 36.431$.

Ley 20 de 1984. Por la cual se reglamenta el ejercicio de la profesión de Ingeniero de Petróleos y se dictan otras disposiciones. Septiembre 14 de 1984. Do N. ${ }^{\circ} 36.768$.

Ley 22 de 1984. Por la cual se reconoce la Biología como una profesión, se reglamenta su ejercicio en el país y se dictan otras disposiciones. Septiembre 17 de 1984. Do N. ${ }^{\circ} 36.768$.

Ley 51 de 1986. Por la cual se reglamenta el ejercicio de las profesiones de Ingeniería Eléctrica, Ingeniería Mecánica y profesiones afines y se dictan otras disposiciones. Octubre 10 de 1986. DO N. ${ }^{\circ} 37.673$.

Ley 28 de 1989. Por la cual se reconoce la Ingeniería Pesquera como una profesión, se reglamenta su ejercicio en el país y se dictan otras disposiciones. Febrero 10 de 1989. Do N. ${ }^{\circ} 38.699$.

Ley 33 de 1989. Por la cual se reglamenta el ejercicio de la profesión de Ingeniero de Transportes y Vías y se dictan otras disposiciones. Febrero 27 de 1989. Do N.³8.721.

Ley 35 de 1989. Sobre ética del odontólogo colombiano. Marzo 08 de 1989. Do N. 38.733.

Ley 43 de 1990. Por la cual se adiciona la Ley 145 de 1960, reglamentaria de la profesión de Contador Público y se dictan otras disposiciones. Diciembre 13 de 1990. DO N. 39.602.

Ley 5 de 1992. Por la cual se expide el Reglamento del Congreso, el Senado y la Cámara de Representantes. Junio 17 de 1992. Do N. ${ }^{\circ} 40.483$.

Ley 62 de 1993. Por la cual se expiden normas sobre la Policía Nacional, se crea un establecimiento público de seguridad social y bienestar para la Policía Nacional, se crea la Superintendencia de Vigilancia y Seguridad Privada y se reviste de facultades extraordinarias al Presidente de la República. Agosto 12 de 1993. Do N. ${ }^{\circ} 40.987$.

Ley 180 de 1995. Por la cual se modifican y expiden algunas disposiciones sobre la Policía Nacional y del Estatuto para la Seguridad Social y Bienestar de la Policía Nacional y se otorgan facultades extraordinarias al Presidente de la República para desarrollar la Carrera Policial denominada "Nivel Ejecutivo", modificar normas sobre estructura orgánica, funciones específicas, disciplina y ética y evaluación y clasificación y normas de la Carrera Profesional de Oficiales, Suboficiales y Agentes. Enero 13 de 1995. Do N. ${ }^{\circ} 41.676$.

Ley 266 de 1996. Por la cual se reglamenta la profesión de enfermería en Colombia y se dictan otras disposiciones. Enero 25 de 1996. Do N. ${ }^{\circ} 42.710$. 
Ley 322 de 1996. Por la cual se crea el Sistema Nacional de Bomberos de Colombia y se dictan otras disposiciones. Octubre 04 de 1996. DO N. ${ }^{\circ} 42.894$.

Ley 435 de 1998. Por la cual se reglamenta el ejercicio de la profesión de Arquitectura y sus profesiones auxiliares, se crea el Consejo Profesional Nacional de Arquitectura y sus profesiones auxiliares, se dicta el Código de Ética Profesional, se establece el Régimen Disciplinario para estas profesiones, se reestructura el Consejo Profesional Nacional de Ingeniería y Arquitectura en Consejo Profesional Nacional de Ingeniería y sus profesiones auxiliares y otras disposiciones. Febrero 10 de 1998. Do N. ${ }^{\circ} 43.241$.

Ley 576 de 2000. Por la cual se expide el Código de Ética para el ejercicio profesional de la medicina veterinaria, la medicina veterinaria y zootecnia y la zootecnia. Febrero 15 de 2000. DO N. ${ }^{\circ} 43.897$.

Ley 578 de 2000. Por medio de la cual se reviste al Presidente de la República de facultades extraordinarias para expedir normas relacionadas con las fuerzas militares y de policía nacional. Marzo 14 de 2000. DO 43.934.

Ley 599 de 2000. Código Penal Colombiano. Julio 24 de 2000. Do N. ${ }^{\circ} 44.097$.

Ley 650 de 2001. Código de Ética Profesional de Optometría. Abril 17 de 2001. Do N.º 44.394.

Ley 668 de 2001. Por medio de la cual se declara anualmente el 18 de agosto como Día Nacional de la Lucha Contra la Corrupción. Julio 30 de 2001. Do N. 44.503.

Ley 734 de 2002. Código Disciplinario Único. Febrero 5 de 2002. Do N.º 44.708.

Ley 836 de 2003. Por la cual se expide el reglamento del Régimen Disciplinario para las Fuerzas Militares. Julio 16 de 2003. DO N. ${ }^{\circ} 45.251$.

Ley 841 de 2003. Por la cual se reglamenta el ejercicio de la profesión de Bacteriología, se dicta el Código de Bioética y otras disposiciones. Octubre 07 de 2003. DO N.º 45.335.

Ley 842 de 2003. Por la cual se modifica la reglamentación del ejercicio de la ingeniería, de sus profesiones afines y de sus profesiones auxiliares, se adopta el Código de Ética Profesional y se dictan otras disposiciones. Octubre 09 de 2003. Do N. ${ }^{\circ} 45.340$.

Ley 911 de 2004. Por la cual se dictan disposiciones en materia de responsabilidad deontológica para el ejercicio de la profesión de Enfermería en Colombia; se establece el régimen disciplinario correspondiente y se dictan otras disposiciones. Octubre 05 de 2004. Do N. 45.693. 
Ley 962 de 2005. Por la cual se dictan disposiciones sobre racionalización de trámites y procedimientos administrativos de los organismos y entidades del Estado y de los particulares que ejercen funciones públicas o prestan servicios públicos. Julio 08 de 2005. DO N.․ 46.023.

Ley 1015 de 2006. Por medio de la cual se expide el Régimen Disciplinario para la Policía Nacional. Febrero 07 de 2006. Do N.4 46.175.

Ley 1090 de 2006. Por la cual se reglamenta el ejercicio de la profesión de Psicología, se dicta el Código Deontológico y Bioético y otras disposiciones. Septiembre 06 de 2006. Do N. ${ }^{4} 46.383$.

Ley 1123 de 2007. Por la cual se establece el Código Disciplinario del Abogado. Enero 22 de 2007. DO N. ${ }^{\circ} 46.519$.

Ley 1193 de 2008. Por la cual se modifica parcialmente la Ley 841 del 7 de octubre de 2003 y se dictan otras disposiciones. Mayo 09 de 2008. Do N. 46.984.

Ley 1240 de 2008. Por la cual se dictan disposiciones en materia de Responsabilidad Deontológica para el ejercicio profesional de la terapia respiratoria en Colombia. Julio 30 de 2008. Do N. ${ }^{\circ}$ 47.066 .

Ley 1264 de 2008. Por medio de la cual se adopta el Código de Ética de los Técnicos Electricistas y se dictan otras disposiciones. Diciembre 26 de 2008. Do N. ${ }^{\circ} 47.214$.

Ley 1409 de 2010. Por la cual se reglamenta el ejercicio profesional de la Archivística, se dicta el Código de Ética y otras disposiciones. Agosto 30 de 2010. DO N.º 47.817.

Ley 1437 de 2011. Código de Procedimiento Administrativo y de lo Contencioso Administrativo. Enero 18 de 2011. DO N. ${ }^{\circ} 47.956$.

Ley 1575 de 2012. Por medio de la cual se establece la Ley General de Bomberos de Colombia. Agosto 21 de 2012. DO 48.530.

Ley 1579 de 2012. Por la cual se expide el estatuto de registro de instrumentos públicos y se dictan otras disposiciones. Octubre 01 de 2012. DO N. 48.570.

Ley 1768 de 2015. Por la cual se establece el procedimiento disciplinario que deberá seguirse para tramitar y decidir los asuntos disciplinarios que conoce el Consejo Profesional Nacional de Arquitectura y sus Profesiones Auxiliares. Octubre 23 de 2015. Do N. ${ }^{\circ} 49.674$.

Ley 1796 de 2016. Por la cual se establecen medidas enfocadas a la protección del comprador de vivienda, el incremento de la seguridad de las edificaciones y el fortalecimiento de la Función 
Pública que ejercen los curadores urbanos, se asignan unas funciones a la Superintendencia de Notariado y Registro y se dictan otras disposiciones. Julio 13 de 2016. Do N.º 49.933.

Ley 1828 de 2017. Por medio de la cual se expide el Código de Ética y Disciplinario del Congresista y se dictan otras disposiciones. Enero 23 de 2017. Do N. ${ }^{\circ} 50.125$.

Ley 1862 de 2017. Por la cual se establecen las normas de conducta del militar colombiano y se expide el Código Disciplinario Militar. Agosto 04 de 2017. Do N. ${ }^{\circ} 50.315$.

Ley 1952 de 2019. Código General Disciplinario. Enero 28 de 2019. DO N.º 50.850.

Nattan Nisimblat. DeRECHO PROBATORIO. TÉCNICAS DE JUICIO ORAL. 4. ${ }^{a}$ ed. Bogotá: Ediciones Doctrina y Ley. (2018).

Organización de las Naciones Unidas (ONU). Declaración Universal de Derechos Humanos. Diciembre 10 de 1948.

Organización de las Naciones Unidas (ONU). Asamblea General. Pacto Internacional de Derechos Civiles y Políticos. Resolución 2200 A (XXI). Diciembre 16 de 1966.

Procuraduría General de la Nación. DERECHO CONVENCIONAL y POTESTAD DISCIPLINARIA. InStRUMENTOS EFECTIVOS CONTRA LA CORRUPCIÓN EN COLOMBIA. TOMO 1. Colección Fortalecimiento Institucional y Ética. (2019). 